\title{
Long-range trends in adult mortality: Models and projection methods
}

John Bongaarts

Population Council

Follow this and additional works at: https://knowledgecommons.popcouncil.org/departments_sbsr-pgy

Part of the Demography, Population, and Ecology Commons, Family, Life Course, and Society Commons, International Public Health Commons, and the Social Statistics Commons How does access to this work benefit you? Let us know!

\section{Recommended Citation}

Bongaarts, John. 2004. "Long-range trends in adult mortality: Models and projection methods," Policy Research Division Working Paper no. 192. New York: Population Council. Version of record: https://doi.org/10.1353/dem.2005.0003 


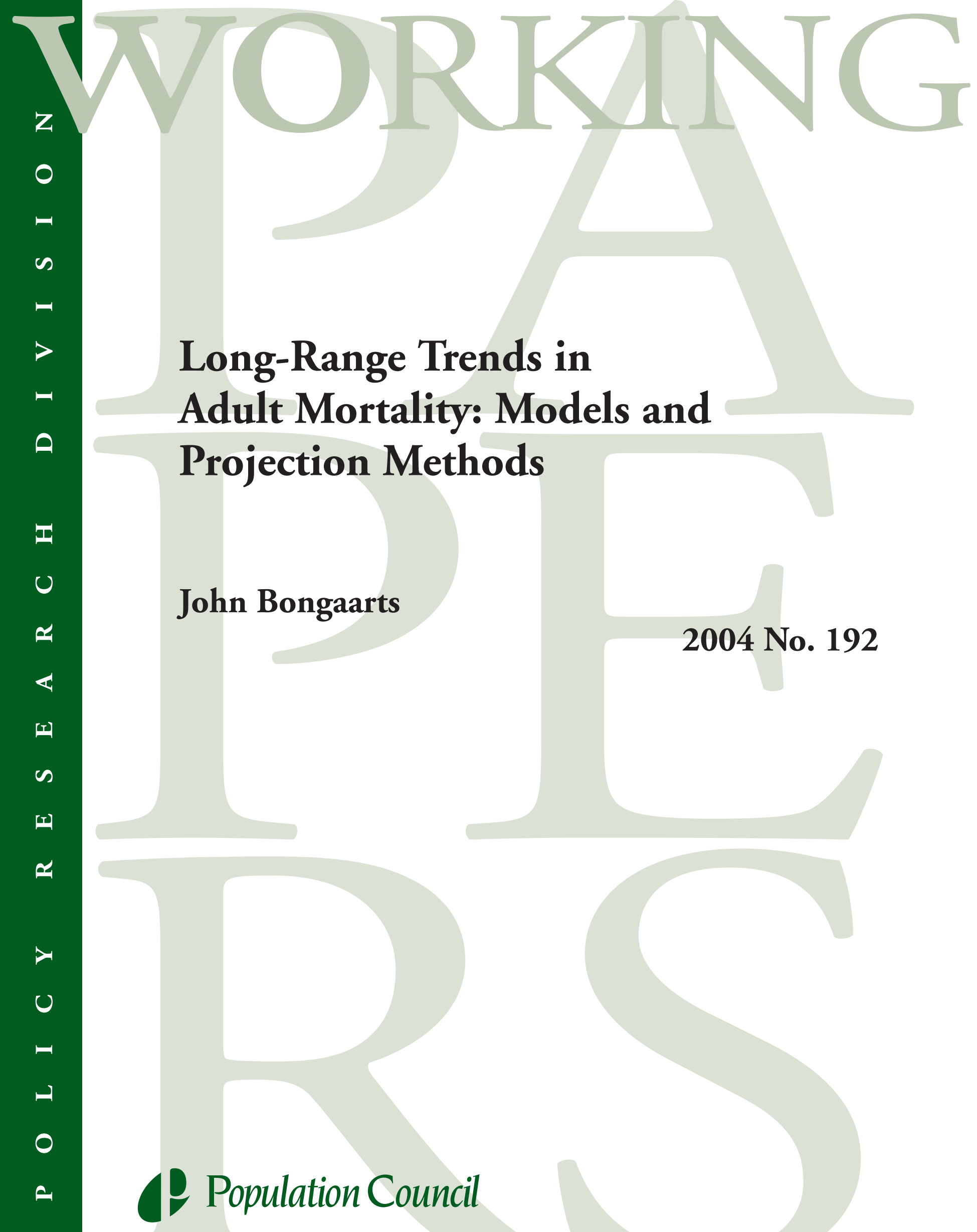




\title{
Long-Range Trends in Adult Mortality: Models and Projection Methods
}

\author{
John Bongaarts
}

John Bongaarts is Vice President, Policy Research Division, Population Council.

Acknowledgements: This research was supported by the Andrew W. Mellon Foundation and the William and Flora Hewlett Foundation. Paul Hewett provided valuable research assistance. An earlier version of this paper was presented in the Session on Mathematical Demography at the Annual Meeting of the Population Association of America, Boston, 13 April 2004. Thomas Buettner, Griffith Feeney, Patrick Gerland, Francois Pelletier, John Wilmoth, and two anonymous reviewers provided helpful comments on an earlier draft.

This material may not be reproduced without written permission from the author. For a list of Policy Research Division Working Papers, including those available for downloading in PDF format, see www.popcouncil.org/publications/wp/prd/rdwplist.html

\section{(C) 2004 The Population Council, Inc.}




\begin{abstract}
This study has two objectives: (1) to test a new version of the logistic model for the pattern of change over time in age-specific adult mortality rates, and (2) to develop a new method for projecting future trends in adult mortality. A test of the goodness-of-fit of the logistic model for the force of mortality indicates that its slope parameter is nearly constant over time. This finding suggests a variant of the model that is called the shifting logistic model. A new projection method based on the shifting mortality model is proposed and compared with the widely used Lee-Carter procedure.
\end{abstract}


Over the past two centuries life expectancy at birth in the industrialized ("developed") world approximately doubled, reaching 79 years for females and 72 years for males in 2000-2005 (United Nations, 2002). Much of this rise is attributable to large reductions in infant and child mortality. Mortality among the young is now so low, however, that further declines will have little impact on future trends in life expectancy. Future increases in life expectancy will therefore require additional reductions in adult mortality. This study examines past trends in the age pattern of adult mortality and discusses their implications for long-range mortality projections.

The description of observed age patterns of adult mortality with mathematical models is one of the oldest and most important topics in demography. The number and complexity of mortality models have grown rapidly since Gompertz proposed the first "law of mortality" in 1825. A good model provides a simple but adequate mathematical description of mortality by age and/or time. The objective is to identify fundamental and persistent patterns in the data and summarize them with as few parameters as possible. Models have found many uses, including smoothing of data, construction of model life tables, comparative analyses, testing of theories, and forecasting (Keyfitz, 1984; Tabeau et al., 2001).

A concise model description of past mortality trends provides the basis for projections. The theory and practice of forecasting mortality have evolved rapidly in recent decades and there are many ways to make forecasts (Keyfitz, 1991; Lee, 1998; Olshansky, 1988; Pollard, 1987; Tabeau et al., 2001). Projections for the short run typically rely on simple extrapolation of historical trends in mortality rates, in life expectancy, or in model parameters. However, in projections for periods of more than a few decades, linear extrapolation can lead to implausible results, and expert judgment is then often used to decide which long-range levels or trends are most probable. For example, experts may identify a target for life expectancy at birth in a future year. This has been the approach used by the United Nations, the World Bank, and many national statistical agencies to make long-range population projections.

This study has two objectives: (1) to test a new version of the logistic model to describe the pattern of change over time in age-specific adult mortality rates, and (2) to develop a new method for projecting future trends in adult mortality. The first part of the paper presents a brief overview of models for the age pattern of adult mortality and a test of the goodness-of-fit of the logistic model for the force of mortality. This test uses data from the Human Mortality Database for females and males aged 25-109 in 14 populations. The results of this exercise suggest a new version of the logistic model that will be called the shifting logistic model, because the senescent component of adult mortality is assumed to shift to higher ages over time. The second part of the paper proposes a new projection method based on the shifting mortality model. The method is compared with the Lee-Carter procedure, which is one of the most widely used methods for projecting mortality. 


\section{MODELS FOR THE FORCE OF MORTALITY}

\section{a) Age pattern}

Mortality rates in a wide range of populations show an approximately exponential rise with age for adults. A simple parametric model proposed by Gompertz (1825) summarizes this pattern:

$$
\mu(x)=\alpha e^{\beta x}
$$

where $\mu(x)$ denotes the force of mortality at age $x$. The two parameters $\alpha$ and $\beta$ are positive; $\alpha$ varies with the level of mortality and $\beta$ measures the rate of increase in mortality with age.

For many purposes the Gompertz model provides a satisfactory fit to adult mortality rates. However, close inspection of the difference between model estimates and observed death rates often reveals systematic underestimation of actual mortality at youngest adult ages (under 40) and overestimation at the oldest ages (over 80). The deviation at lower ages is addressed by Makeham (1860) with the addition of a constant to the Gompertz model:

$$
\mu(x)=\alpha e^{\beta x}+\gamma
$$

The new parameter $\gamma$ is usually referred to as background mortality, which is the same for all ages. A detailed analysis of (2) is provided by Gavrilov and Gavrilova (1991).

The Makeham model represents a clear improvement over the Gompertz model at younger ages, but it still overestimates mortality at the oldest ages. This deviation can be addressed in a number of ways, most simply by the following logistic model (Thatcher, 1999; Thatcher et al., 1998):

$$
\mu(x)=\frac{\alpha e^{\beta x}}{1+\alpha e^{\beta x}}+\gamma
$$

At lower adult ages the force of mortality estimated with models (3) and (2) are very similar, because the denominator of the first term in (3) is close to 1.0 At the oldest ages, however, the two models diverge as (3) levels off at $1+\gamma$ while (2) has no limit.

More complex logistic models with additional parameters have also been proposed (Beard, 1971; Horiuchi and Wilmoth, 1998; Perks, 1932; Thatcher et al., 1998). On the basis of a detailed comparison of different models, Thatcher (1999) and Thatcher et al. (1998) recommend (3) because it provides an excellent fit to mortality rates over the entire adult age range with relatively few parameters.

The good fit of the logistic model (3) is demonstrated in Figure 1, which presents observed and estimated values of the force of mortality $\mu(x)$ for Swedish females aged 25-109 in 1850, 1950, and 2000. The proportion of the variance explained by the model equals 0.9994 in 1850, 0.9996 in 1950, and 0.9985 in 2000. 
To confirm these results for other populations the model given by (3) was fitted to annual mortality data from 1950 to 2000 for 14 countries, separately for males and females. All countries in the Human Mortality Database outside Eastern European were included. Table 1 presents averages of annual estimates for the three parameters in the logistic model $(\alpha, \beta$ and $\gamma)$ for females and males in each of the 14 countries for all available years 1950-2000. ${ }^{1}$ These results are discussed further below but for now it should be noted that the model fits very well in all these countries (see next to last column in Table 1). The fit is about the same for females $\left(R^{2}\right.$ averages 0.9993 for the 14 countries) as for males ( $R^{2}$ averages 0.9996$)$.

Although the simple logistic model is well suited for present purposes, its fit is not perfect. An examination of differences between observed and fitted values reveals small systematic overestimation of mortality between ages 60 and 80 , as well as some underestimation at the highest ages among females in a number of countries. This pattern is consistent with the findings of Himes et al. (1994).

In the following analysis of trends in adult mortality it is useful to distinguish between senescent mortality, which rises with age, and background mortality, which does not vary with age (Gavrilov and Gavrilova, 1991; Horiuchi and Wilmoth, 1998; Makeham, 1860). The sum of these two components equals the force of mortality:

$$
\mu(x, t)=\mu_{s}(x, t)+\mu_{b}(t)
$$

where $\quad \mu_{s}(x, t)=$ senescent force of mortality

$$
\mu_{b}(t)=\text { background force of mortality }
$$

For the logistic model the first term on the right hand side of (3) equals the senescent force of mortality $\mu_{s}(x, t)$, and the background parameter $\gamma(t)$ equals the background force of mortality $\mu_{b}(t)$.

Figure 2 plots model estimates of these two components for Swedish females in 1850,1950 , and 2000. The senescent component rises linearly from age 25 to about age 75 , because in this age range the denominator of the senescent component of (3) is close to 1.0, and the remaining exponential term in the numerator becomes a straight line when plotted on a logarithmic scale as is the case in Figure 2. At ages above about 75 the rate of increase in the force of mortality with age declines in the logistic model, and at very high ages the senescent force of mortality $\mu_{s}(x, t)$ approaches 1.0. The age-invariant background component (plotted as horizontal lines in Figure 2) has declined sharply over time from 0.0071 in 1850 to 0.00078 in 1950 and to 0.00013 in 2000 . The senescent and background components in Figure 2 add up in each year to the overall model estimate of the force of mortality plotted in Figure 1. At high ages background mortality is small compared to senescent mortality and it may be ignored for many analytic purposes, especially in contemporary countries with high life expectancy.

\section{b) Trend over time}

Trends in adult mortality can be summarized with time series of the three 
parameters of the logistic model, $\alpha(t), \beta(t)$, and $\gamma(t)$. Figures 3a-c present estimated trends in these parameters for each of the 14 countries from 1950 to 2000. Several conclusions can be drawn from these results. There is considerable variation among countries in the level parameter $\alpha(t)$, but the trend in this parameter is typically downward. The same is true for background mortality $\gamma(t)$ (see Figure 3c), but there is less variation among countries in $\gamma(t)$ than in $\alpha(t)$. In addition, declines in background mortality are mostly confined to the period 1950 to 1975 . After 1975 there appears to be little systematic trend in $\gamma(t)$ in many of these countries, suggesting that background mortality has reached a low-level plateau.

The most interesting finding in Figure $3 \mathrm{~b}$ is that values of the slope parameter $\beta(t)$ are nearly constant for each population. Similar patterns are observed for males (data not shown). This finding confirms earlier observations by Gavrilov and Gavrilova (1991) and Thatcher (1999). In fact, the near constancy of the slope parameter extends further into the past. For example, for Swedish females $\beta(t)$ averaged 0.112 for 1850-1900, 0.119 for $1900-1950$, and 0.117 for $1950-2000$.

The conclusion about the lack of variation with time in the slope parameter $\beta(t)$ is confirmed in Table 1, which presents averages of annual estimates of the coefficients of variation in the parameters of the logistic model $\alpha(t), \beta(t)$, and $\gamma(t)$ for females and males in 14 countries for the period 1950-2000. The coefficient of variation of the slope parameter $\beta(t)$ is small, averaging just 2.2 percent for females and 3.0 percent for males. In contrast, the coefficients of variation for the level and background parameters, $\alpha(t)$ and $\gamma(t)$, are at least an order of magnitude larger for both males and females. Clearly, the level and background parameters are much more variable than the slope parameter.

\section{c) Shifting logistic model}

The finding that slope parameter $\beta(t)$ is nearly constant suggests a variant of the logistic model in which this parameter is assumed fixed over time for a population. The senescent component of the standard model (3) then simplifies to

$$
\mu_{s}(x, t)=\frac{\alpha(t) e^{\beta x}}{1+\alpha(t) e^{\beta x}}
$$

and the total force of mortality is given by

$$
\mu(x, t)=\frac{\alpha(t) e^{\beta x}}{1+\alpha(t) e^{\beta x}}+\gamma(t)
$$

In this formula $\alpha(t)$ and $\gamma(t)$ are the only time-varying parameters. The value of the slope parameter $\beta$ can differ among populations and may take different values for males and females, but it is constant with respect to time.

A change in the senescent force of mortality from $\mu_{s}\left(x, t_{0}\right)$ at time $t_{0}$ to $\mu_{s}(x, t)$ at time $t$ is conventionally interpreted as a rise or decline in mortality rates. Formula (5) 
offers an alternative and unconventional description of changes in the force of mortality. Instead of interpreting mortality as rising or falling, the schedule of the force of senescent mortality can be viewed as shifting to higher or lower ages over time. This interpretation is possible because (5) has an interesting and very useful property: the age pattern of the senescent force of mortality $\mu_{s}(x, t)$ at time $t$ is the same as at an earlier time $t_{0}$ except that the function has shifted to higher (lower) ages as senescent mortality falls (rises). The senescent force of mortality at age $x$ in year $t$ is identical to the value in an earlier year $t_{0}$ at age $x-S(t)$ except around age zero. As a result, (5) can be written as

$$
\mu_{s}(x, t)=\frac{\alpha\left(t_{0}\right) e^{\beta(x-S(t))}}{1+\alpha\left(t_{0}\right) e^{\beta(x-S(t))}}
$$

where $S(t)$ equals the amount of the shift in years up or down the age axis between $t_{0}$ and $t$ (equation (7) holds for $x>S(t)$, and $\mu_{s}(x, t)=0$ for $\left.x<S(t)\right)$. As shown in Appendix A, the conventional up-down and the alternative shifting interpretations are formally equivalent for the logistic model with

$$
S(t)=-\frac{\ln \left(\alpha(t) / \alpha\left(t_{0}\right)\right)}{\beta}
$$

That is, a change in the senescent force of mortality between $t_{0}$ and $t$ can be described with (5) as a change in the level parameter $\alpha\left(t_{0}\right)$ to $\alpha(t)$ or equivalently with (7) as a shift by $S(t)$ years.

The idea of a shifting mortality schedule can be clarified further by introducing the senescent life expectancy at birth denoted $e_{s}(t)$ and defined as

$$
e_{s}(t)=\int_{0}^{\infty} \exp \left\{-\int_{0}^{a} \mu_{s}(x, t) d x\right\} d a
$$

It equals the average age at death of a newborn subjected to senescent force of mortality $\mu_{s}(x, t)$, assuming no background mortality and no non-senescent mortality at younger ages. The shift to higher or lower ages in the force of senescent mortality function between $t_{0}$ and $t$ is closely approximated by the change in senescent life expectancy between $t_{0}$ and $t$ :

$$
S(t) \approx e_{s}(t)-e_{s}\left(t_{0}\right)
$$

because $\mu_{s}(x, t)$ is very small around age zero. 
The pattern of the force of senescent mortality $\mu_{s}(x, t)$ given by (5) and (7) will be referred to as the shifting logistic model. It is a member of a more general class of models for which the shifting assumption holds with

$$
\mu_{s}(x, t)=\mu_{s}\left(x-S(t), t_{0}\right)
$$

The shifting logistic model always implies (11), but the shifting assumption given by (11) may hold even when $\mu_{s}(x, t)$ does not follow a logistic (more on this below). It should be emphasized that, in general, the shifting property applies only to senescent mortality and not to all adult mortality.

The shifting is evident in Figure 2, where the lines for senescent mortality in 1850, 1950, and 2000 have similar shapes with the schedules for later years moved to higher ages compared to earlier years. The shift equaled 4 years between 1850 and 1950 and 7 years between 1950 and 2000. A shifting pattern for mortality change was proposed earlier by Kannisto et al. (1996), and some of its implications are examined by Bongaarts and Feeney $(2002,2003)$.

The shifting logistic model describes changes over time in the age pattern of senescent mortality with only one time-varying parameter (either the level $\alpha(t)$ or the shift $S(t))$. This advantage is offset by some loss in the goodness-of-fit. However, the proportion of variance explained by the shifting model with constant slope parameter $\beta$ is still an impressive 0.9993 for females and 0.9995 for males (average of 14 populations and all years from 1950 to 2000). The last column of Table 1 presents the $R^{2}$ values for males and females in each of the 14 countries with the slope $\beta$ held constant at its average for 1950-2000. These results are only slightly smaller than the $R^{2}$ for the logistic model with a variable $\beta(t)$ presented in the next to last column in Table 1.

These results indicate that the shifting logistic model provides a good general description of age patterns of adult mortality in many countries for the past half century. The implications of this finding for mortality projections are discussed next (see Appendix B for an analysis of the implications of the model for rates of change in mortality).

\section{Projecting Adult Mortality Rates}

The models for the force of mortality discussed in the preceding section will now be applied to gain insights into projection methods. After a brief description of the LeeCarter method, a new forecasting approach will be proposed.

\section{a) The Lee-Carter method}

Lee and Carter (1992) described a new statistical method for modeling and forecasting mortality by age that has been adopted widely. For example, the US Census Bureau uses the Lee-Carter forecast as a benchmark for their long-run forecast of life expectancy (Hollman et al., 2000), and a Social Security Technical Advisory Panel recommended the adoption of the method (Technical Panel on Assumptions and Methods, 1999; Lee and Miller, 2001). Projections of mortality for the G7 countries by 
Tuljapurkar et al. (2000) also use this method. On the basis of the recommendations of an expert group, the United Nations Population Division has prepared its long-range projections to 2300 for all countries in the world with a variant of the Lee-Carter model (United Nations, 2003). Recent discussion of the model and its applications can be found in Lee (1998), Lee (2000), Lee and Miller (2001), Booth et al. (2002), Carter and Prskawetz (2003), and Tabeau et al. (2001).

The Lee-Carter method is based on the following mortality model:

where

$$
\ln [m(x, t)]=a(x)+b(x) \kappa(t)+\varepsilon(x, t)
$$

$m(x, t)=$ central death rate at age $x$ and time $t$

$\kappa(t)=$ index of level of mortality

$a(x)=$ age-specific constants describing the general pattern of mortality by age

$b(x)=$ age-specific constants for the relative speed of mortality change

$\varepsilon(x, t)=$ residual

This model provides a good fit to past age-specific mortality rates in the US, explaining 93 percent of the within-age-group variance between 1900 and 1987 (Lee and Carter, 1992).

Equation (12) provides the basis for making mortality projections. A projection requires only the extrapolation of the index $\kappa(t)$, because $a(x)$ and $b(x)$ are estimated from past data and are held constant for the duration of the projection. An ARIMA time-series model is usually used for the index $\kappa(t)$, and Lee and Carter (1992) and other analysts have assumed a random walk with a drift that describes past trends in $\kappa(t)$ well. The implication of assuming a linear trend in $\kappa(t)$ to continue into the future is that mortality rates at all ages follow an exponential decline. That is, the projected proportional rate of mortality decline $\rho(x, t)$ in a future year $t$ varies by age but it is assumed to remain equal at each age to the rate observed in the past:

$$
\rho(x, t)=\rho_{h}(x)
$$

where $\rho_{h}(x)$ is the observed rate of decline in the death rate at age $x$ over some historical period $h$ that ends in the base year of the projection. To ensure robust results Lee and Carter recommend that estimates of past rates of decline $\rho_{h}(x)$ be based on historical data for periods of several decades.

The model has several attractive features: a relatively simple demographic model captures the main trends in patterns of past mortality change; forecasting is based on persistent long-term trends and involves no subjective judgment; and the application of statistical time-series methods provides probabilistic confidence intervals for the forecast (Lee and Miller, 2001; Booth et al., 2002). In addition, tests in several populations indicate that projections made with this method are quite accurate over short time horizons (Lee and Miller, 2001). The Lee-Carter method, however, also has a limitation that becomes increasingly significant as the projection duration rises. The central 
assumption that the rate of decline in mortality at each age remains invariant over time is violated in several countries in recent decades. Instead of being constant, rates of mortality improvement have tended to decline over time at younger ages while rates of improvement have risen at older ages (Booth et al., 2002; Carter and Prskawetz, 2003; Lee, 2000; Lee and Miller, 2001). Appendix B confirms that the age pattern of the rate of mortality decline $\rho(x, t)$ has varied over time and examines the factors underlying this variation. This finding implies that rates of improvement are likely to continue to change in the future. By not allowing such change, the Lee-Carter method may produce implausible results in projections over many decades. Some investigators have attempted to address this limitation by adding complexity and additional parameters to the LeeCarter model (Booth et al., 2002; Carter and Prskawetz, 2003). The alternative approach proposed next provides a simpler solution.

\section{b) A new projection procedure}

The shifting logistic model suggests several ways to project future age-specific rates of adult mortality. The simplest approach consists of fitting the logistic model with a fixed slope parameter to past data, followed by extrapolation of the model parameters. The preparation of such a basic projection consists of the following four steps:

1) Fit the three-parameter logistic model (3) to mortality schedules for a selected period before the base year of the projection. This fitting exercise produces time series for each of the three parameters in the logistic model, $\alpha(t), \beta(t)$, and $\gamma(t)$. As discussed above, Figures 3a,b,c illustrate this step for females in 14 countries from 1950 to 2000. (These estimates were obtained with the nonlinear least squares routine in STATA.)

2) Fix the value of the slope parameter $\beta$ at its average value and fit the two-parameter model (6) to the same data. The resulting time series of level parameter $\alpha(t)$ and background parameter $\gamma(t)$ differ slightly from those obtained in step 1. Figures $4 \mathrm{a}$ and $4 \mathrm{~b}$ present these new estimates for the same 14 countries from 1950 to 2000 (note logarithmic scale).

3) Extrapolate the level parameter $\alpha(t)$ and background parameter $\gamma(t)$ obtained in step 2 for the desired projection duration. ${ }^{2}$

4) Construct future adult mortality schedules as logistic curves using (6) based on the extrapolated values of parameters $\alpha(t)$ and $\gamma(t)$.

This four-step projection procedure is straightforward and relatively easy to apply, and it should give satisfactory results in populations in which the logistic model (6) fits well. However, in some populations the differences between the observed and fitted mortality rates may be significant and systematic at some ages. In such cases one of the following variants of the above basic projection procedure will be preferable: 
Variant 1. Although the standard logistic model (5) fits very well, more complex logistic models provide an even better fit. As noted by Thatcher (1999) a simple fourparameter logistic model can be obtained by multiplying the numerator of the senescent force of mortality $\mu_{s}(x, t)$ in (5) by an additional parameter $\lambda$. In the three-parameter model used in this study $\lambda$ is assumed equal to 1 . Allowing $\lambda$ to deviate from 1 should provide a better general description of age patterns of mortality, in particular at the highest ages. In projections $\lambda$ may be held constant as is the case now for slope parameter $\beta$. The implementation of this variant follows the above four steps, but in step 1 four parameters - $\alpha(t), \beta(t), \gamma(t)$, and $\lambda(t)$-are estimated and in step 2, $\beta(t)$ and $\lambda(t)$ are held constant while reestimating $\alpha(t)$ and $\gamma(t)$.

Variant 2. A still more flexible approach is to not rely on a logistic model in step 4 and to assume only that the shifting assumption holds in the future. That is, instead of constructing future adult mortality schedules as logistic curves, senescent mortality is projected as a shifted version of the observed schedule in the base year, using equation (11). In this approach, the age pattern of senescent mortality observed in the base year is shifted to higher ages in future years while maintaining its original shape. ${ }^{3}$ The amount of the shift $S(t)$ for each future year is estimated from the projected trend in level parameter $\alpha(t)$ with (8). Background mortality is projected separately based on extrapolation of background parameter $\gamma(t)$.

The choice of whether to use the basic method or one of these two variants should be informed by how well the simple three-parameter logistic model fits recent observed mortality rates. If the fit is extremely good and only random deviations are present, then the basic method may be adequate. If the fit is good at all ages except among the oldest old, then variant 1 with the four-parameter logistic is a better choice. Finally, if systematic deviations between model and observed rates are present, then variant 2 should give the best results. This variant is more complex to implement but it has clear advantages: there are no discontinuities in trends in age-specific mortality rates at the beginning of the projection, and the country-specific features of the mortality schedule that are not captured by the logistic are preserved in the projection. ${ }^{4}$

A brief comment on the method of extrapolation of the level and background parameters is in order. As shown in Figure $4 \mathrm{a}$, the values of the level parameter as measured by $\log [\alpha(t)]$ have declined at a nearly constant pace over the past half century in the 14 countries. Extrapolation of $\log [\alpha(t)]$ can therefore rely on the same time-series model used by Lee-Carter to project their index $k(t)$, i.e. a random walk with a drift. The near linear trends in $\log [\alpha(t)]$ observed in Figure 4a suggest that it is reasonable to assume this trend will continue for a few more decades, but it is not clear whether this will be the case in very long-range projections. It is interesting to note that, according to equations (8) and (10), linear extrapolation of $\log [\alpha(t)]$ yields a linear extrapolation of senescent life expectancy, $e_{s}(t)$. 
The same extrapolation approach can be used to project values of the logarithm of background mortality. However, it is evident from Figure $4 \mathrm{~b}$ that the pace of decline in $\log [\gamma(t)]$ is not as steady as in $\log [\alpha(t)]$. Alternative nonlinear methods might therefore be preferable for extrapolating background mortality, but these will not be examined further here. Values of background mortality have reached such low levels in contemporary developed countries that a small error is of little consequence in projections.

Since this study focuses on adult mortality, no attempt will be made to propose alternative ways to project child and young adult mortality. Moreover, the shifting model does not apply to mortality patterns at ages below 25 . No improvement over conventional methods can therefore be suggested. Further details on projection methods for youngest age groups can be found in United Nations (2002), Pollard (1987), and Tabeau et al. (2001).

\section{c) Illustrative applications}

A detailed evaluation of the new projection methods and comparison with the Lee-Carter approach are beyond the scope of this study, but Figure 5 presents an illustrative application for adult mortality of Swedish females. The initial year for the projection is 1975 and the projection from 1975 to 2000 is based on extrapolation of estimated parameters from 1950 to 1975 . Figure 5 presents three mortality schedules for 2000: the observed one and two projections, obtained with the new method and with LeeCarter. ${ }^{5}$ Both methods performed well and their projected age-specific mortality rates are very similar to the observed rates in 2000 . The observed life expectancy at age 25 rose from 49.9 years in 1950 to 54.1 years in 1975 and to 57.5 years in 2000 . The projected life expectancies at age 25 in 2000 were 57.7 years for the new method and 58.0 years for Lee-Carter. In this application the differences between the two methods are minor.

Figure 6 presents another illustrative application in which the initial year for the projection is 2000 , and the projection from 2000 to 2100 is based on extrapolation of estimated parameters from 1950 to 2000. In this long-range projection, the two methods produce quite different age patterns in 2100. Compared with the new method the LeeCarter projection expects very little improvement in mortality at the highest ages and very large improvements in age group 60-80. It is not obvious which projection is preferable. However, a simple theoretical argument supports the view that the new approach gives more robust long-range projections for the age pattern of mortality than Lee-Carter. The Lee-Carter method is equivalent to extrapolating past trends in mortality rates for each age group at its own exponential rate (McNown, 1992; Lee and Miller, 2001). This is potentially problematic because any differences between the $b(x)$ values of successive age groups will eventually cause differences between the projected mortality rates of these age groups either to become very large or to turn negative. In either case the Lee-Carter method may forecast implausible age patterns in the very long run. In contrast, the new method assures that the age structure of senescent mortality remains plausible, regardless of the duration of the projection. 


\section{CONCLUSION}

Past age patterns in the force of mortality among adults are well described with a simple logistic model in which the slope parameter is assumed constant over time within each population. The model includes separate components for background and senescent adult mortality, which are each summarized with one time-varying parameter. Despite its simplicity, this model captures the main features of complex changes over time in agespecific mortality rates among adults.

The constancy of the slope parameter in this model implies that the senescent component of the force of mortality shifts to higher or lower ages as mortality conditions improve or deteriorate for adults. This shifting model introduces an alternative way of thinking about mortality change. The conventional view is that senescent mortality change implies increases or decreases in age-specific mortality rates. The proposed new view considers a change in senescent mortality rates to be the result of delays in the timing of death. This alternative perspective is captured in the shifting logistic model, which provides a parsimonious description of past trends in senescent mortality.

The shifting mortality model also provides the basis for a new method for making projections of age-specific mortality that has certain advantages over existing procedures. In particular, the method addressed a key weakness in the Lee-Carter method (i.e., the assumption that the age-specific rate of decline in mortality remains constant over time). Further research is needed to establish whether and under what conditions the proposed new method produces more accurate projections than existing methods. 


\section{APPENDIX A: RELATIONSHIP BETWEEN LEVEL PARAMETER $\alpha(t)$ AND THE SHIFT IN THE} SENESCENT FORCE OF MORTALITY

A decline in the value of the level parameter from $\alpha\left(t_{0}\right)$ at time $t_{0}$ to $\alpha(t)$ at time $t$ implies a decline in senescent mortality from $\mu_{s}\left(x, t_{0}\right)$ to $\mu_{s}(x, t)$ as estimated from (5).

Let the ratio of $\alpha(t)$ to $\alpha\left(t_{0}\right)$ be denoted $p(t)$ with

$$
p(t)=\frac{\alpha(t)}{\alpha\left(t_{0}\right)}
$$

Substitution of (A1) in (5) gives

$$
\begin{aligned}
\mu_{s}(x, t) & =\frac{p(t) \alpha\left(t_{0}\right) e^{\beta x}}{1+p(t) \alpha\left(t_{0}\right) e^{\beta x}} \\
& =\frac{\alpha\left(t_{0}\right) e^{\beta(x+\ln (p(t)) / \beta)}}{1+\alpha\left(t_{0}\right) e^{\beta(x+\ln (p(t)) / \beta)}}
\end{aligned}
$$

Define

$$
S(t)=-\frac{\ln (p(t))}{\beta}=-\frac{\ln \left(\alpha(t) / \alpha\left(t_{0}\right)\right)}{\beta}
$$

Substitution of (A3) in (A2) gives

$$
\begin{aligned}
\mu_{s}(x, t) & =\frac{\alpha\left(t_{0}\right) e^{\beta(x-S(t))}}{1+\alpha\left(t_{0}\right) e^{\beta(x-S(t))}} \\
& =\mu_{s}\left(x-S(t), t_{0}\right)
\end{aligned}
$$

A decline in $\alpha$ between $t_{0}$ and $t$ is equivalent to a shift of $S(t)$ years in the schedule of the force of mortality, with $S(t)$ given by (A3). 


\section{APPENDIX B. MODELS FOR THE RATE OF CHANGE IN THE FORCE OF MORTALITY}

Past studies of mortality trends have gained important insights by examining the rate of change in the force of mortality with respect to age or time (Horiuchi and Coale, 1990; Horiuchi and Wilmoth, 1998; Keyfitz, 1977; Vaupel, 1986; Vaupel and Romo, 2003). The shifting model provides useful insights into the factors that determine trends in the rate of change in the force of mortality.

\section{- Rate of change by age}

The relative derivative of the force of mortality $\mu(x, t)$ with respect to age is defined as

$$
k(x, t)=\frac{1}{\mu(x, t)} \frac{\partial \mu(x, t)}{\partial x}
$$

and is referred to as the age-specific rate of mortality change with age (Horiuchi and Coale, 1990) or the life table aging rate (Horiuchi and Wilmoth, 1998).

Figure B1 plots observed and model estimated values of $k(x, t)$ for Swedish females in 1850, 1950, and 2000. The pattern is bell-shaped and varies over time. It is also somewhat different for males than for females (data not shown).

To interpret these changes with age and over time it is useful to decompose $k(x, t)$ into two additive factors representing the senescent component $k_{s}(x, t)$ and the background component $k_{b}(x, t)$ (see Horiuchi and Wilmoth, 1998, for a slightly different decomposition):

$$
k(x, t)=k_{s}(x, t)+k_{b}(x, t)
$$

The senescent component $k_{s}(x, t)$ is defined as the aging rate that would be observed in the absence of background mortality, and $k_{b}(x, t)$ equals the difference between $k(x, t)$ and $k_{s}(x, t)$.

As shown in Appendix C, for the shifting logistic model

$$
\begin{aligned}
& k_{s}(x, t)=\frac{\beta}{1+\alpha(t) e^{\beta x}}=\beta\left[1-\mu_{s}(x, t)\right] \\
& k_{b}(x, t)=\frac{-\beta}{1+[1+1 / \gamma(t)] \alpha(t) e^{\beta x}}
\end{aligned}
$$

Figure B2 plots the model senescent component $k_{s}(x, t)$ for Swedish females in 1850 , 1950 , and 2000. At the youngest ages $k_{s}(x, t)$ is approximately constant and equal to $\beta$ because $\mu_{s}(x, t)<<1$. With advancing age $k_{s}(x, t)$ declines and reaches 0 at very high ages. The schedules for $k_{s}(x, t)$ and $\mu_{s}(x, t)$ shift together to higher (lower) ages as senescent life expectancy rises (falls).

Figure B3 plots model estimates of the background component $k_{b}(x, t)$ for Swedish females in 1850,1950 , and 2000 . The value of $k_{b}(x, t)$ is negative and rises from 
- $\beta$ at very young ages to 0 at the oldest ages. An interesting property of the $k_{b}(x, t)$ schedule is that it shifts to higher/lower ages. But, in general, this shifting occurs at a different rate from the shifting in $\mu_{s}(x, t)$ and $k_{s}(x, t)$. In most countries $k_{b}(x, t)$ either moves more slowly to the right than $k_{s}(x, t)$ (when $\gamma(t)$ declines but less rapidly than $\alpha(t)$ ) or shifts to the left (when $\gamma(t)$ declines more rapidly than $\alpha(t)$ ). For Swedish females the background component has clearly moved to the left between 1850 and 1950 and again between 1950 and 2000 because of a very rapid decline in background mortality.

The background and senescent components combine to produce the overall pattern of $k(x, t)$ as shown in Figure B4 for Swedish females in 1950. In general, shifts over time of the ascending portion of the bell shape at lower ages are attributable to shifts in the background component $k_{b}(x, t)$, and shifts in the descending portion of the bell at higher ages are caused by shifts in the senescent component $k_{s}(x, t)$ (see related discussion in Horiuchi and Wilmoth, 1998). As a result, the overall bell-shaped pattern for $k(x, t)$ exhibits complex changes and can move to the left or right and become wider or narrower depending on trends in $k_{s}(x, t)$ and $k_{b}(x, t)$, which in turn are determined by $\alpha(t), \beta$, and $\gamma(t)$. This makes it difficult to draw conclusions about trends in senescent mortality from the overall shape of $k(x, t)$. It is therefore preferable to analyze the background and senescent components separately or to limit the analysis to highest ages, where senescent mortality dominates.

\section{- Rate of change over time}

The relative derivative of the force of mortality with respect to time is defined as

$$
\rho(x, t)=-\frac{1}{\mu(x, t)} \frac{\partial \mu(x, t)}{\partial t}
$$

and is called the rate of improvement in mortality (Keyfitz, 1977; Vaupel, 1986; Vaupel and Romo, 2003).

Annual estimates for $\rho(x, t)$ tend to fluctuate widely, and the empirical analysis of this variable is therefore usually restricted to averages over periods of one or more decades. Figure B5 plots observed and model estimated values of $\rho(x, t)$ for Swedish females from 1850 to 1950 and from 1950 to 2000. For both periods $\rho(x, t)$ declined with age. To interpret these changes with age and over time it is again useful to decompose $\rho(x, t)$ into two additive factors, the senescent component $\rho_{s}(x, t)$ and the background component $\rho_{b}(x, t)$ :

$$
\rho(x, t)=\rho_{s}(x, t)+\rho_{b}(x, t)
$$

The senescent component $\rho_{s}(x, t)$ is defined as the rate of mortality improvement that would be observed in the absence of background mortality, and $\rho_{b}(x, t)$ equals the difference between $\rho(x, t)$ and $\rho_{s}(x, t)$. 
As shown in Appendix D, if the shifting assumption (11) holds, then

$$
\begin{aligned}
& \rho_{s}(x, t)=\dot{e}_{s}(t) k_{s}(x, t) \\
& \rho_{b}(x, t)=\dot{e}_{s}(t) k_{b}(x, t)-\frac{1}{\mu(x, t)} \frac{d \mu_{b}(t)}{d t}
\end{aligned}
$$

where $\dot{e}_{s}(t)$ denotes the derivative of senescent life expectancy with respect to time: $\dot{e}_{s}(t)=d e_{s}(t) / d t$. Note that (B7) and (B8) are valid even if senescent mortality does not follow the logistic, provided the shifting assumption holds. If the shifting logistic model does apply, substitution of (B3) in (B7) gives

$$
\rho_{s}(x, t)=\dot{e}_{s}(t) \beta\left[1-\mu_{s}(x, t)\right]
$$

and $\gamma(t)$ can be substituted for $\mu_{b}(t)$ in (B8). Equation (B9) is a more general version of the formula $\rho_{s}(t)=\dot{e}_{s}(t) \beta$ derived by Vaupel (1986) for the Gompertz model. Note also that when background mortality is constant, $\rho(x, t)=\dot{e}_{s}(t) k(x, t)$.

Figure B6 plots model estimates of $\rho_{s}(x, t)$ obtained from (B9) for Swedish females from 1850 to 1950 and from 1950 to 2000 . The age pattern of $\rho_{s}(x, t)$ (but not its level) is the same as for $k_{s}(x, t)$ : at the lowest ages $\rho_{s}(x, t)$ is constant with age, equal to $\beta \dot{e}_{s}(t)$, because $\mu_{s}(x, t)<<1$. With advancing age $\rho_{s}(x, t)$ declines and reaches 0 at very high ages following the same pattern of relative decline as $k_{s}(x, t)$. The level of $\rho_{s}(x, t)$ is substantially higher for 1950-2000 than for 1850-1950 because senescent life expectancy rose at a more rapid pace in the former than in the latter period. The schedule for $\rho_{s}(x, t)$ shifts to the right as senescent life expectancy rises, as was the case for $k_{s}(x, t)$ and $\mu_{s}(x, t)$.Variations in the schedule $\rho_{s}(x, t)$ over time and with age are therefore the net result of two factors: (1) up/down movements over time due to variation in $\dot{e}_{s}(t)$ and (2) shifts to higher (lower) ages as $e_{s}(t)$ rises (falls).

Model estimates of the background component of the rate of mortality improvement for Swedish females from 1850 to 1950 and from 1950 to 2000 are plotted in Figure B7. Over these two periods the decline in background mortality has been rapid and the second term on the right hand side of (B8) has dominated. This term is directly proportional to the rate of change in background mortality, and, since $\gamma(t)$ has declined over time (i.e., its derivative is negative), $\rho_{b}(x, t)$ has been positive, as is evident in Figure B7. The more rapidly $\gamma(t)$ declines, the more positive $\rho_{b}(x, t)$ becomes. In addition, $\rho_{b}(x, t)$ declines sharply with age and approaches zero at high ages. (Note that $\rho_{b}(x, t)$ is negative when background mortality is constant and senescent life expectancy is rising, because $k_{b}(x, t)$ is negative.)

The senescent and background components combine to produce the patterns of change in the overall rate of improvement in mortality $\rho(x, t)$ as illustrated in Figure B8 for Swedish females for the period 1950-2000. Below about age 70 the decline in $\rho(x, t)$ with age is attributable to a decline in the background component, while the 
senescent component is approximately constant at $\beta \dot{e}_{s}(t)$. At ages above $70, \rho_{b}(x, t)$ is near zero and $\rho_{s}(x, t)$ declines, reaching zero at very old ages.

The pattern of $\rho(x, t)$ varies widely over time and among countries as shown in Figures B9-B12, which compare model estimates of $\rho(x, t)$ for 1950-1960 and 19851995 for England and Wales, France, Italy, and Japan. To facilitate the interpretation of these results the values of $\beta \dot{e}_{s}(t)$ for 1950-1960 and 1985-1995 are plotted as horizontal dashed lines. In the middle adult ages (around age 70) $\rho(x, t)$ is close to this line. At younger ages $\rho(x, t)$ is either above (1950-1960) or below (1985-1995) this line depending largely on the rate of decline in $\gamma(t)$. At older ages $\rho(x, t)$ declines with age and shifts to higher ages as senescent life expectancy rises.

Given the complexity of changes in $\rho(x, t)$ it is difficult to draw conclusions from them about overall trends in adult mortality. As was the case for $k(x, t)$ it is preferable to analyze the background and senescent components of $\rho(x, t)$ separately. Limiting the analysis to highest ages where the senescent component dominates is somewhat helpful, but it is difficult to determine whether changes at the highest ages are due to shifting (caused by a change in the level of senescent life expectancy) or to an up or down movement (caused by variation in the rate of change in senescent life expectancy).

This analysis of the rate of change in the force of mortality leads to two conclusions. First, the age pattern of $\rho(x, t)$ has changed substantially in recent decades in many countries. This makes it likely that the rate of mortality improvement will not be constant in the future as assumed in some existing projection methods. Second, the factors responsible for the variation in $\rho(x, t)$ include different trends in background and senescent mortality and a shifting pattern of senescent mortality. 


\section{APPENDIX C : DeCOMPOSITION OF THE AGING RATE FOR THE SHIFTING LOGISTIC} MODEL

The objective is to derive equations (B3) and (B4). The first step is to find an equation relating $k(x, t)$ to the parameters in the shifting logistic model. Substitution of (6) in (B1) yields

$$
\begin{aligned}
k(x, t) & =\frac{\frac{\partial \mu(x, t)}{\partial x}}{\mu(x, t)} \\
& =\frac{\frac{\partial}{\partial x}\left[\frac{\alpha(t) e^{\beta x}}{1+\alpha(t) e^{\beta x t}}+\gamma(t)\right]}{\left[\frac{\alpha(t) e^{\beta x}}{1+\alpha(t) e^{\beta x t}}+\gamma(t)\right]} \\
& =\frac{\frac{\beta \alpha(t) e^{\beta x}}{\left[1+\alpha(t) e^{\beta x}\right]^{2}}}{\left[\frac{\alpha(t) e^{\beta x}}{1+\alpha(t) e^{\beta x t}}+\gamma(t)\right]} \\
& =\frac{\beta \alpha(t) e^{\beta x}}{\left[1+\alpha(t) e^{\beta x}\right]\left[\alpha(t) e^{\beta x}+\gamma(t)\left(1+\alpha(t) e^{\beta x}\right)\right]}
\end{aligned}
$$

The senescent component $k_{b}(x, t)$ of $k(x, t)$ is defined as the aging rate that would be observed in the absence of background mortality. Substitution of $\mu_{b}(x, t)=\gamma(t)=0$ in $(\mathrm{C} 1)$ gives

$$
\begin{aligned}
k_{s}(x, t) & =\frac{\beta}{1+\alpha(t) e^{\beta x}} \\
& =\beta\left[1-\mu_{s}(x, t)\right]
\end{aligned}
$$

thus confirming (B3).

The background component $k_{s}(x, t)$ of $k(x, t)$ is defined as the difference between $k(x, t)$ and $k_{s}(x, t)$ :

$$
k_{b}(x, t)=k(x, t)-k_{s}(x, t)
$$

Substitution of (C1) and (C2) in (C3) yields 


$$
k_{b}(x, t)=\frac{\beta \alpha(t) e^{\beta x}}{\left[1+\alpha(t) e^{\beta x}\right]\left[\alpha(t) e^{\beta x}+\gamma(t)\left(1+\alpha(t) e^{\beta x}\right)\right]}-\frac{\beta}{1+\alpha(t) e^{\beta x}}
$$

Simplification of (C4) gives (B4). 


\section{APPENDIX D: DECOMPOSITION OF THE RATE OF MORTALITY IMPROVEMENT}

The aim of this appendix is to derive equations B7 and B8 for the senescent and background components of the rate of mortality improvement, provided the shifting assumption (11) holds.

-Senescent component $\rho_{s}(x, t)$.

By definition the senescent component equals the rate of mortality observed when background mortality equals zero, so that

$$
\rho_{s}(x, t)=-\frac{1}{\mu_{s}(x, t)} \frac{\partial \mu_{s}(x, t)}{\partial t}=-\frac{\partial \ln \mu_{s}(x, t)}{\partial t}
$$

To derive (B7) from (D1) it is necessary first to examine the relationship between $k_{s}(x, t)$ and $\mu_{s}(x, t)$ in more detail. The relative derivative of $\mu_{s}(x, t)$ with respect to age is defined as

$$
k_{s}(x, t)=\frac{1}{\mu_{s}(x, t)} \frac{\partial \mu_{s}(x, t)}{\partial x}
$$

so that

$$
\mu_{s}(x, t)=\mu_{s}(0, t) \exp \left[\int_{0}^{x} k_{s}(a, t) d a\right]
$$

If the shifting assumption (11) holds then changes in $k_{s}(x, t)$ occur through the same shifts to higher/lower ages as in $\mu_{s}(x, t)$ :

$$
k_{s}(x, t)=k_{s}\left(x-S(t), t_{0}\right)
$$

where $S$ equals the amount of the shift in years up or down the age axis $\mu_{s}(x, t)$ or $k_{s}(x, t)$ between $t$ and $t_{0}$. When senescent life expectancy is rising $S(t)$ is positive, and (D3) holds for $x>S(t)$ with $k_{s}(x, t)=0$ for $x<S(t)$; when $S$ is negative, (D3) holds for $x>0$ ). The shift $S$ is a function of $t$ and $t_{0}$, but subscripts will be dropped to simplify the notation. In most populations it is possible to select the base year $t_{0}$ so that $\mathrm{S}$ is positive because senescent life expectancy has risen between $t$ and $t_{0}$. The derivation below will assume that this is the case.

With $S(t)>0, \mu_{s}(S(t), t)=\mu_{s}\left(0, t_{0}\right)$ and substitution of this and of (D4) in (D3) gives

$$
\mu_{s}(x, t)=\mu_{s}\left(0, t_{0}\right) \exp \left\{\int_{S(t)}^{x} k_{s}\left(a-S(t), t_{0}\right) d a\right\}
$$


for $x>S(t)$ and $\mu_{s}(x, t)=0$ otherwise.

Substitution of (D5) in (D1) now gives

$$
\begin{aligned}
\rho_{s}(x, t) & =-\frac{\partial \ln \left[\mu_{s}\left(0, t_{0}\right) e^{\left.-\int_{S}^{x} k_{s}\left(a-S(t), t_{0}\right) d a\right)}\right]}{\partial t} \\
& =-\frac{\partial}{\partial t} \int_{S(t)}^{x} k_{s}\left(a-S(t), t_{0}\right) d a \\
& =-\frac{\partial}{\partial t} \int_{0}^{a-S(t)} k_{s}\left(y, t_{0}\right) d y \\
& =\frac{d S(t)}{d t} k_{s}\left(x-S(t), t_{0}\right)
\end{aligned}
$$

And substitution of (D4) and (10) in (D6) yields

$$
\begin{aligned}
\rho_{s}(x, t) & =\frac{d S(t)}{d t} k_{s}(x, t) \\
& =\frac{d e_{s}(t)}{d t} k_{s}(x, t)
\end{aligned}
$$

thus confirming (B7).

-Background component $\rho_{b}(x, t)$.

The background component of the rate of mortality improvement is defined as

$$
\rho_{b}(x, t)=\rho(x, t)-\rho_{s}(x, t)
$$

Substitution of 


$$
\rho(x, t)=-\frac{1}{\mu(x, t)} \frac{\partial \mu_{s}(x, t)}{\partial t}-\frac{1}{\mu(x, t)} \frac{\partial \mu_{b}(x, t)}{\partial t}
$$

and of (D7) in (D8) gives

$$
\begin{aligned}
\rho_{b}(x, t) & =-\frac{1}{\mu(x, t)} \frac{\partial \mu_{s}(x, t)}{\partial t}-\frac{1}{\mu(x, t)} \frac{\partial \mu_{b}(x, t)}{\partial t}-\frac{d e_{s}(t)}{d t} k_{s}(x, t) \\
& =\frac{\mu_{s}(x, t)}{\mu(x, t)} \frac{d e_{s}(t)}{d t} k_{s}(x, t)-\frac{1}{\mu(x, t)} \frac{\partial \mu_{b}(x, t)}{\partial t}-\frac{d e_{s}(t)}{d t} k_{s}(x, t) \\
& =\left[\frac{\mu_{s}(x, t)}{\mu(x, t)}-1\right] \frac{d e_{s}(t)}{d t} k_{s}(x, t)-\frac{1}{\mu(x, t)} \frac{\partial \mu_{b}(x, t)}{\partial t}
\end{aligned}
$$

The first term on the right hand side of (D10) can be simplified by noting that $d \mu_{b}(x, t) / d x=0$ because background mortality does not vary with age. This implies that

$$
\frac{\partial \mu_{s}(x, t)}{\partial x}=\frac{\partial \mu(x, t)}{\partial x}
$$

and therefore

$$
\frac{k(x, t)}{k_{s}(x, t)}=\frac{\mu_{s}(x, t)[\partial \mu(x, t) / d x]}{\mu(x, t)\left[\partial \mu_{s}(x, t) / d x\right]}=\frac{\mu_{s}(x, t)}{\mu(x, t)}
$$

Substitution of (D12) in (D10) with $k(x, t)=k_{s}(x, t)+k_{b}(x, t)$ gives

$$
\begin{aligned}
\rho_{b}(x, t) & =\left[\frac{k(x, t)}{k_{s}(x, t)}-1\right] \frac{d e_{s}(t)}{d t} k_{s}(x, t)-\frac{1}{\mu(x, t)} \frac{\partial \mu_{b}(x, t)}{\partial t} \\
& =k_{b}(x, t) \frac{d e_{s}(t)}{d t}-\frac{1}{\mu(x, t)} \frac{\partial \mu_{b}(x, t)}{\partial t}
\end{aligned}
$$

thus confirming (B8). 
A simpler expression for $\rho(x, t)$ can be obtained if background mortality is constant, as appears to be approximately the case over the past two decades in the 14 countries plotted in Figure 3c. With $d \mu_{b}(t)(x, t) / d t=0$ the second term on the right side of (D13) disappears. The sum of the senescent and background components then becomes

$$
\rho(x, t)=\frac{d e_{s}(t)}{d t} k_{s}(x, t)+\frac{d e_{s}(t)}{d t} k_{b}(x, t)=\frac{d e_{s}(t)}{d t} k(x, t)
$$

In this special case the age pattern of $\rho(x, t)$ has the same shape as $k(x, t)$, and the entire schedule of $\rho(x, t)$ is proportional to the rate of change in senescent life expectancy. The three schedules $\mu(x, t), k(x, t)$ and $\rho(x, t)$ maintain their shape over time and shift to higher/lower ages at the same pace as senescent life expectancy rises/falls. 


\section{Notes}

1) Data are available for most years from 1950 to 2000 in the 14 countries, but in several cases data for the last year(s) in the late 1990s or the early 1950s are missing. For details see www.mortality.org. The nonlinear least squares routine in STATA was used to obtain estimates of the parameters in the logistic model.

2) To avoid the influence of random fluctuations in past estimates of $\alpha(t)$ and $\gamma(t)$ on the projection, it is usually desirable to smooth these time series by taking a three- or fiveyear moving average before extrapolating.

3) The baseline estimate of $\mu_{s}\left(x, t_{0}\right)$ is obtained by subtracting the estimated background mortality $\gamma\left(t_{0}\right)$ from the observed force of mortality $\mu\left(x, t_{0}\right)$.

4) The new projection method can also be applied in populations for which mortality data are available only for a single year or period. This is the case for many developing countries, where mortality data are often limited. The available information for one period provides the baseline estimates of levels of background and senescent mortality, but in the absence of past data analysts will have to make assumptions about future trends in the parameters $\alpha(t)$ and $\gamma(t)$.

5) Annual estimates of parameters and age-specific death rates from 1950 to 1975 used in these projections are smoothed by taking a five-year moving average. 


\section{REFERENCES}

Beard, R.E. 1971. "Some Aspects of Theories of Mortality, Cause of Death Analysis, Forecasting and Stochastic Processes." In W. Brass (ed.), Biological Aspects of Demography. New York: Barnes \& Noble, Inc.

Bongaarts, J. and G. Feeney. 2002. “How Long Do We Live?” Population and Development Review 28(1):13-29. . 2003. "Estimating Mean Lifetime." Proceedings of the National Academy of Sciences US, 100 (23):13127-13133.

Booth, H.J. Maindonald and L. Smith. 2002. "Applying Lee-Carter Under Conditions of Variable Mortality Decline.” Population Studies 56:325-336.

Carter, R. and A. Prskawetz. 2003. "Examining Structural Shifts in Mortality Using the Lee-Carter Method." mimeo.

Gavrilov, L.A. and N.S. Gavrilova. 1991. The Biology of Life Span: A Quantitative Approach. V.P. Skulachev (ed.). Chur, Switzerland: Harwood Academic Publishers.

Himes, C. L., S. H. Preston, and G.A. Condran. 1994. "A Relational Model of Mortality at Older Ages in Low Mortality Countries.” Population Studies 48:269-291.

Hollman, F.W., T.J. Mulder, and J.E. Kallan. 2000. "Methodology and Assumptions for the Population Projections of the United States: 1999 to 2100.” Working Paper 38, Population Division, U.S. Bureau of the Census.

Horiuchi, S. and A.J. Coale. 1990. "Age Patterns of Mortality for Older Women: An Analysis Using the Age-specific Rate of Mortality Change with Age." Mathematical Population Studies 2(4): 245-267.

Horiuchi, S. and J.R. Wilmoth. 1998. "Deceleration in the Age Pattern of Mortality at Older Ages." Demography 35 (4): 391-412.

Kannisto, V. 1994. Development of Oldest-old Mortality, 1950-1990: Evidence from 28 Developed Countries. Denmark: Odense University Press.

.1996. The Advancing Frontier of Survival: Life Tables for Old Age. Denmark: Odense University Press.

Kannisto, V., J. Lauritsen, A. R. Thatcher, and J.W. Vaupel. 1994. "Reductions in Mortality at Advanced Ages: Several Decades of Evidence from 27 Countries." Population and Development Review 20(4): 793-810. 
Keilman, N. 1997. "Ex-post Errors in Official Population Forecasts in Industrialized Countries.” Journal of Official Statistics (Statistics Sweden) 13: 245-277.

Keyfitz, N. 1977. Applied Mathematical Demography. New York: Wiley.

. 1981. "The Limits of Population Forecasting." Population and Development Review 7(4): 579-593.

. 1984. "Choice of Function for Mortality Analysis: Effective Forecasting Depends on a Minimum Parameter Representation." In J. Vallin, J.H. Pollard, and L. Heligman (eds.), Methodologies for the Collection and Analysis of Mortality Data. Liege, Belgium: Ordina Editions.

. 1991. "Experiments in the Projection of Mortality." Canadian Studies in Population 18(2): 1-17.

Lee, R. 1998. "Probabilistic Approaches to Population Forecasting," Population and Development Review 24:156-190 (Lutz, Vaupel, and Ahlburg, eds.), Supplement: Frontiers of Population Forecasting.

. 2000. "The Lee-Carter Method for Forecasting Mortality, with Various Extensions and Applications." North American Actuarial Journal 4(1): 80-93.

Lee, R.D. and L.R. Carter. 1992. "Modeling and Forecasting U.S. Mortality." Journal of the American Statistical Association 87(419): 659-671.

Lee, R. and T. Miller. 2001. "Evaluating the Performance of the Lee-Carter Method for Forecasting Mortality." Demography 38(4): 537-549.

National Research Council. 2000. Beyond Six Billion. J. Bongaarts and R. Bulatao, editors. Washington DC: National Research Council.

McNown, R. 1992. "Comment" on Lee, Ronald D. and Lawrence R. Carter, "Modeling and Forecasting U.S. Mortality." Journal of the American Statistical Association 87(419): 659-672.

McNown, R. and A. Rogers. 1989. "Forecasting Mortality: A Parameterized Time Series Approach." Demography 26(4): 645-660.

Olshansky, S. J. 1988. “On Forecasting Mortality,” The Milbank Quarterly 66(3): 482530.

Pollard, J.H. 1987. "Projection of Age-specific Mortality Rates." Population Bulletin of the United Nations. Nos. 21-22. New York: United Nations. Pp. 55-69. 
Tabeau, E., A. Jeths, and C. Heathcote. 2001. Forecasting Mortality in Developed Countries. Dordrecht, the Netherlands: Kluwer Academic Publishers.

Technical Panel on Assumptions and Methods. 1999. Report to the Social Security Advisory Board, available at www.ssab.gov/Rpt99.pdf

Thatcher, A.R. 1999. "The Long-term Pattern of Adult Mortality and the Highest Attained Age." Journal of the Royal Statistical Society 162 Part 1: 5-43.

Thatcher A.R., V. Kannisto, and J.W. Vaupel. 1998. The Force of Mortality at Ages 80 to 120. Odense: Odense University Press.

Tuljapurkar, S., N. Li, and C. Boe. 2000. "A Universal Pattern of Mortality Decline in the G7 Countries." Nature 405: 789-792 (letter).

Vaupel, J.W. 1986. "How Change in Age-specific Mortality Affects Life Expectancy." Population Studies 40(1):147-157.

Vaupel J.W. and V. C. Romo. 2003. "Decomposing Change in Life Expectancy: a Bouquet of Formulas in Honor of Nathan Keyfitz's 90th Birthday." Demography 40(2): 201-216.

United Nations. 2002. World Population Prospects 2002. New York: United Nations. . 2003. Long-Range Population Projections: Proceedings of the United Nations Technical Working Group on Long-Range Population Projections. United Nations Population Division. (available at www.un.org/esa/population/ publications/longrange/long-range_working-paper_final.PDF) 
Table 1: Parameters of the logistic model for adult mortality fitted to observed agespecific death rates for ages 25-109, average of annual estimates for all available years from 1950 to 2000 in 14 countries

\begin{tabular}{|c|c|c|c|c|c|c|c|c|}
\hline & \multicolumn{2}{|c|}{$\begin{array}{l}\alpha(t) \times 10^{5} \\
(\text { level ) }\end{array}$} & \multicolumn{2}{|c|}{$\begin{array}{c}\beta(t) \\
\text { (slope) }\end{array}$} & \multicolumn{2}{|c|}{$\begin{array}{c}\gamma(t) \\
\text { (background) }\end{array}$} & \multirow{2}{*}{$\begin{array}{c}\mathrm{R}^{2} \\
\text { Variable } \beta(t) \\
\text { Average }\end{array}$} & \multirow{2}{*}{$\begin{array}{c}\mathrm{R}^{2} \\
\text { Constant } \beta \\
\text { Average }\end{array}$} \\
\hline & Average & $\begin{array}{l}\text { Coef. of } \\
\text { variation }\end{array}$ & Average & $\begin{array}{l}\text { Coef. of } \\
\text { variation }\end{array}$ & Average & $\begin{array}{l}\text { Coef. of } \\
\text { variation }\end{array}$ & & \\
\hline FEMALES & & & & & & & & \\
\hline Austria & 0.87 & 0.310 & 0.117 & 0.016 & 0.00052 & 0.512 & 0.9991 & 0.9991 \\
\hline Canada & 1.55 & 0.292 & 0.106 & 0.019 & 0.00035 & 0.389 & 0.9996 & 0.9996 \\
\hline Denmark & 1.52 & 0.203 & 0.108 & 0.042 & 0.00029 & 0.658 & 0.9988 & 0.9987 \\
\hline England & 1.42 & 0.184 & 0.109 & 0.016 & 0.00027 & 0.729 & 0.9997 & 0.9997 \\
\hline Finland & 0.75 & 0.349 & 0.119 & 0.019 & 0.00053 & 0.633 & 0.9991 & 0.9991 \\
\hline France & 0.85 & 0.443 & 0.115 & 0.027 & 0.00068 & 0.341 & 0.9992 & 0.9991 \\
\hline Italy & 0.73 & 0.346 & 0.118 & 0.020 & 0.00052 & 0.556 & 0.9996 & 0.9996 \\
\hline Japan & 0.76 & 0.628 & 0.118 & 0.033 & 0.00093 & 0.969 & 0.9996 & 0.9995 \\
\hline Netherlands & 0.76 & 0.181 & 0.116 & 0.016 & 0.00035 & 0.304 & 0.9994 & 0.9993 \\
\hline Norway & 0.65 & 0.189 & 0.117 & 0.016 & 0.00032 & 0.465 & 0.9992 & 0.9992 \\
\hline Sweden & 0.69 & 0.290 & 0.117 & 0.019 & 0.00038 & 0.330 & 0.9992 & 0.9992 \\
\hline Switzerland & 0.62 & 0.551 & 0.120 & 0.031 & 0.00047 & 0.301 & 0.9991 & 0.9991 \\
\hline USA & 2.18 & 0.253 & 0.101 & 0.018 & 0.00042 & 0.183 & 0.9996 & 0.9996 \\
\hline W.Germany & 0.85 & 0.228 & 0.116 & 0.011 & 0.00046 & 0.346 & 0.9994 & 0.9994 \\
\hline $\begin{array}{l}\text { Average } \\
\text { females }\end{array}$ & 1.01 & 0.318 & 0.114 & 0.022 & 0.00046 & 0.480 & 0.9993 & 0.9993 \\
\hline \multicolumn{9}{|l|}{ MALES } \\
\hline Austria & 2.98 & 0.215 & 0.106 & 0.018 & 0.00097 & 0.267 & 0.9995 & 0.9994 \\
\hline Canada & 3.97 & 0.333 & 0.100 & 0.039 & 0.00066 & 0.180 & 0.9996 & 0.9995 \\
\hline Denmark & 2.66 & 0.278 & 0.106 & 0.039 & 0.00057 & 0.296 & 0.9994 & 0.9993 \\
\hline England & 2.82 & 0.272 & 0.107 & 0.020 & 0.00032 & 0.482 & 0.9995 & 0.9995 \\
\hline Finland & 5.77 & 0.351 & 0.099 & 0.035 & 0.00088 & 0.473 & 0.9994 & 0.9993 \\
\hline France & 4.20 & 0.249 & 0.101 & 0.019 & 0.00098 & 0.242 & 0.9995 & 0.9995 \\
\hline Italy & 2.54 & 0.332 & 0.107 & 0.032 & 0.00076 & 0.431 & 0.9996 & 0.9996 \\
\hline Japan & 2.23 & 0.366 & 0.108 & 0.017 & 0.00104 & 0.809 & 0.9998 & 0.9998 \\
\hline Netherlands & 1.99 & 0.318 & 0.109 & 0.036 & 0.00042 & 0.421 & 0.9996 & 0.9995 \\
\hline Norway & 1.96 & 0.330 & 0.109 & 0.039 & 0.00067 & 0.334 & 0.9996 & 0.9995 \\
\hline Sweden & 1.48 & 0.299 & 0.112 & 0.030 & 0.00073 & 0.207 & 0.9997 & 0.9996 \\
\hline Switzerland & 1.80 & 0.408 & 0.111 & 0.035 & 0.00090 & 0.236 & 0.9994 & 0.9994 \\
\hline USA & 6.36 & 0.412 & 0.094 & 0.041 & 0.00087 & 0.348 & 0.9998 & 0.9996 \\
\hline W.Germany & 2.92 & 0.173 & 0.105 & 0.017 & 0.00070 & 0.297 & 0.9998 & 0.9998 \\
\hline $\begin{array}{l}\text { Average } \\
\text { males }\end{array}$ & 3.12 & 0.310 & 0.105 & 0.030 & 0.00075 & 0.359 & 0.9996 & 0.9995 \\
\hline
\end{tabular}

Source: Estimated from data in Human Mortality Database 
Figure 1: Age-specific death rates, observed and estimated with logistic model, Swedish females

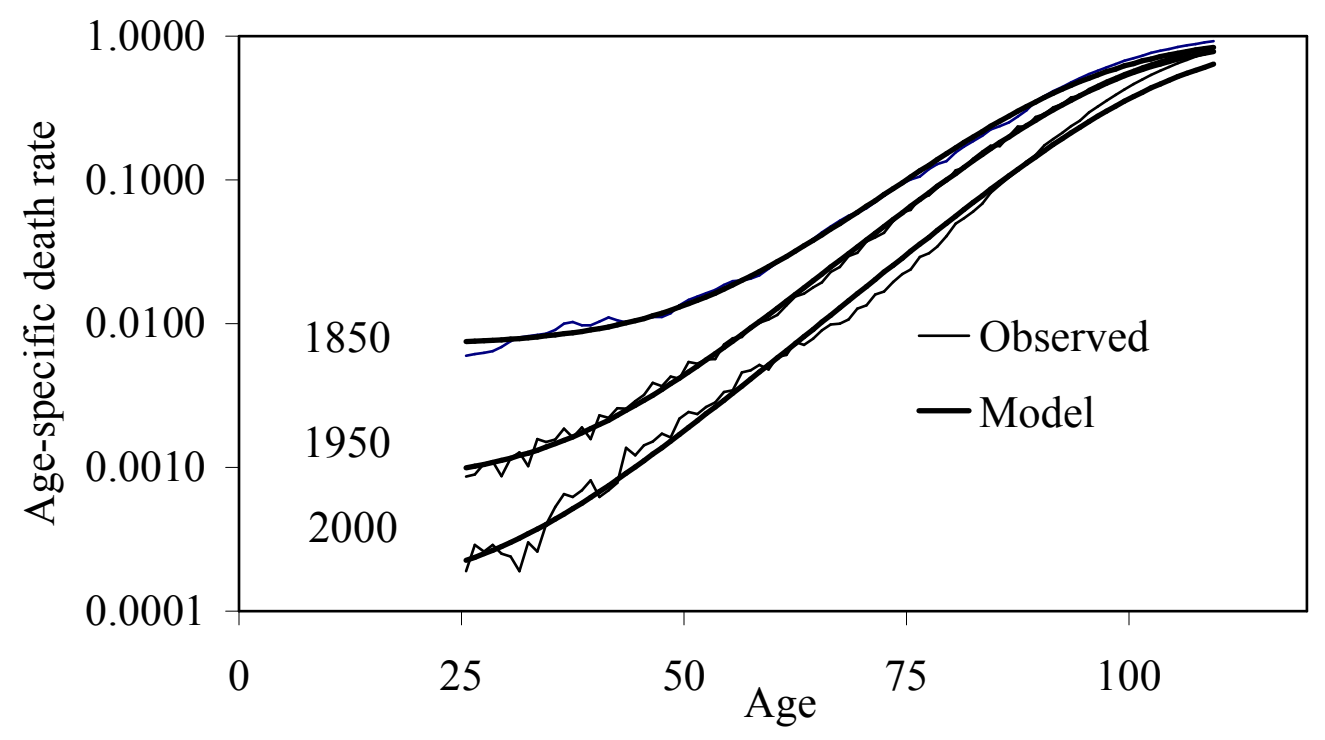

Figure 2: Model estimates of senescent and background death rates by age, Swedish females

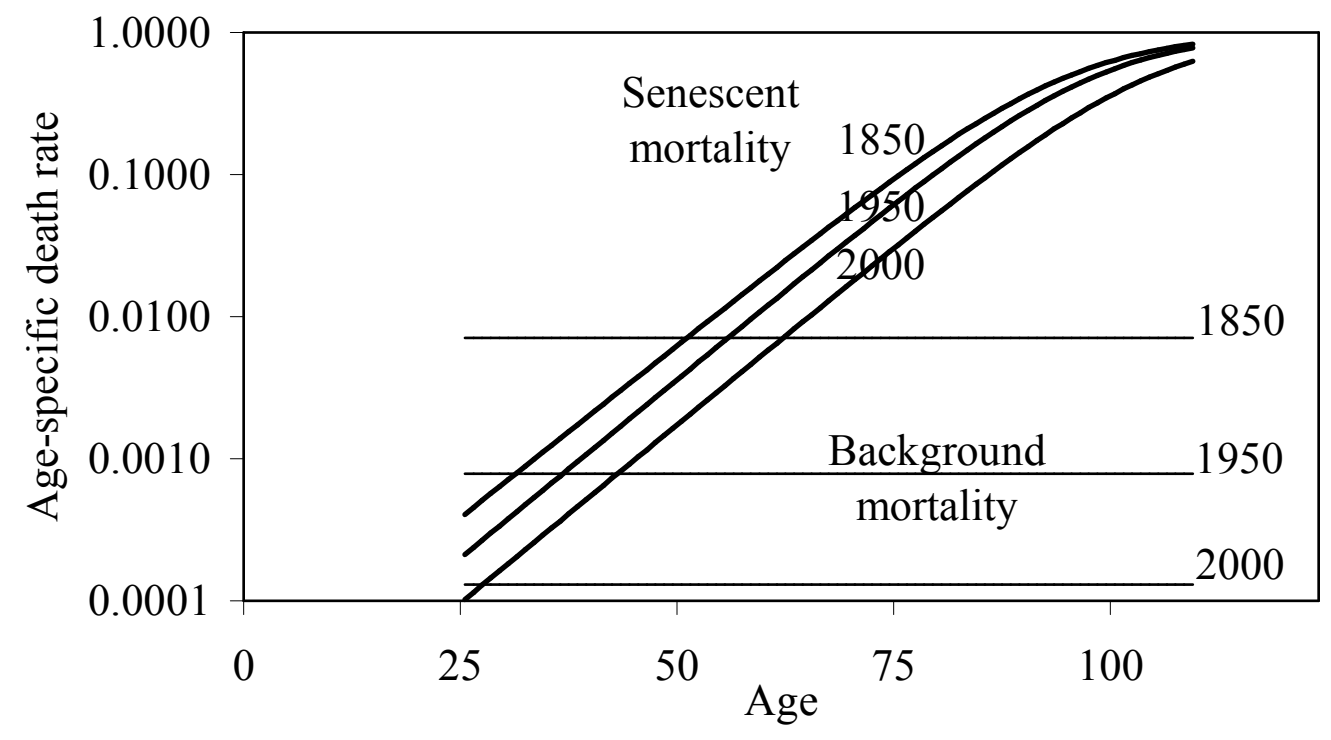


Figure 3a: Estimates of level parameter $\alpha$ in the logistic model for 14 countries, females, 1950-2000

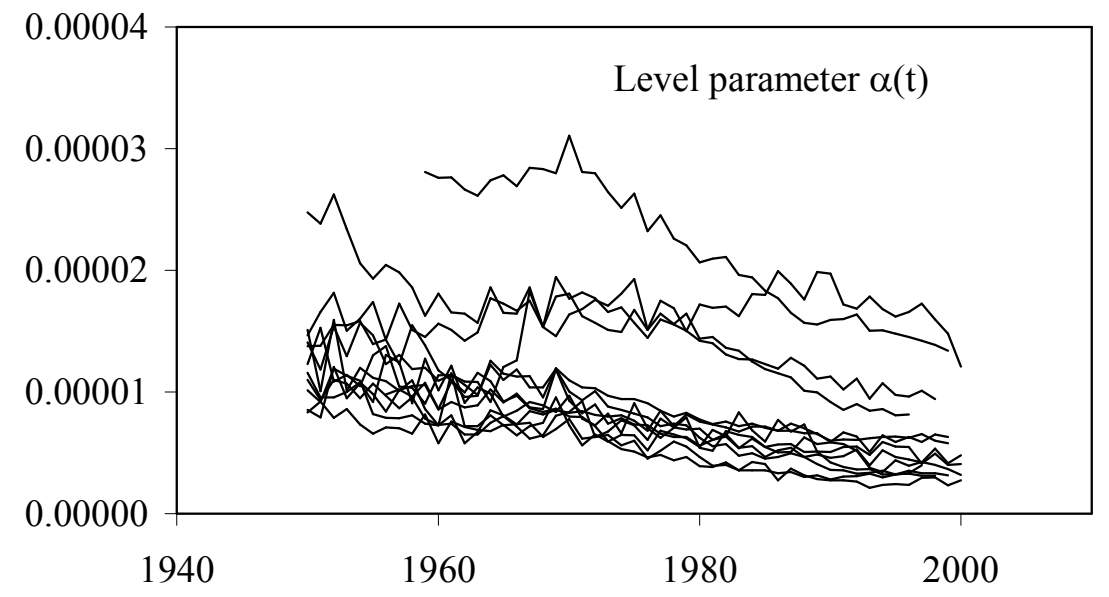

Figure $3 \mathrm{~b}$ : Estimates of slope parameter $\beta$ in the logistic model for 14 countries, females, 1950-2000

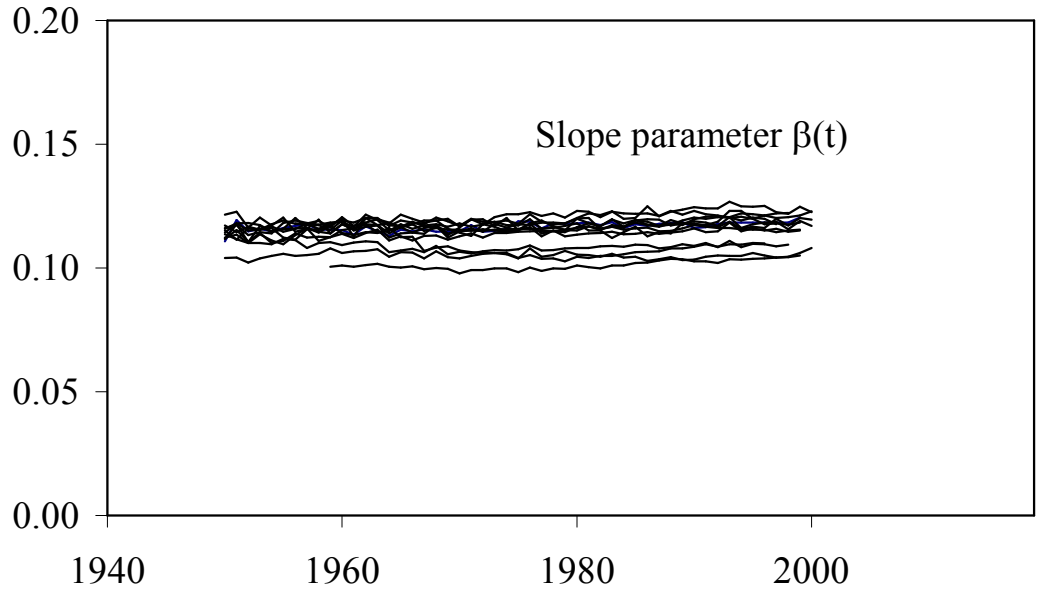

Figure 3c: Estimates of background parameter $\gamma$ in the logistic model for 14 countries, females, 1950-2000

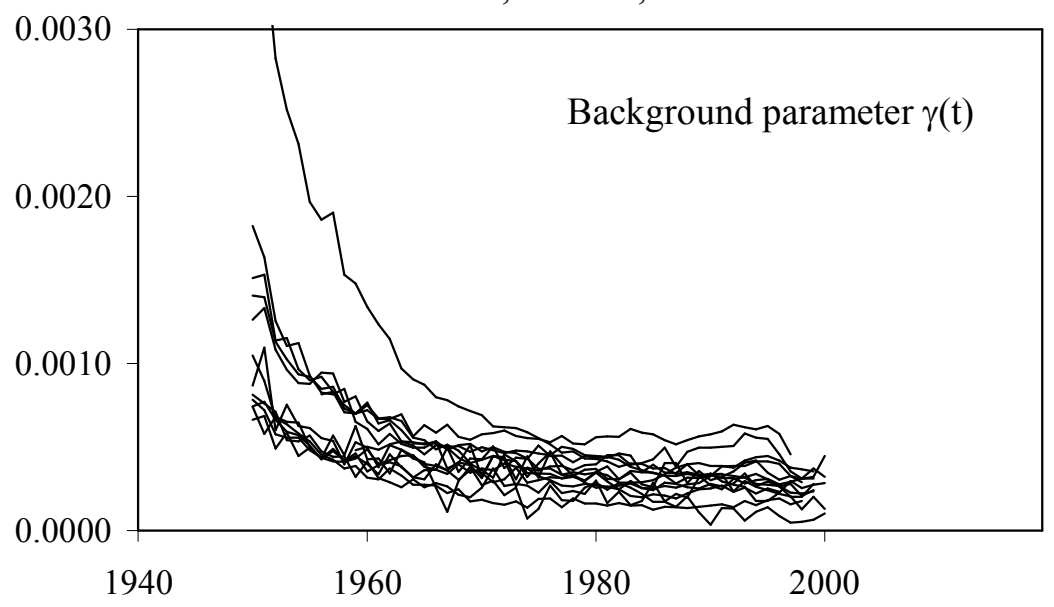


Figure 4a: Estimates of level parameter $\alpha$ in the shifting logistic model (constant $\beta$ ) for 14 countries, females

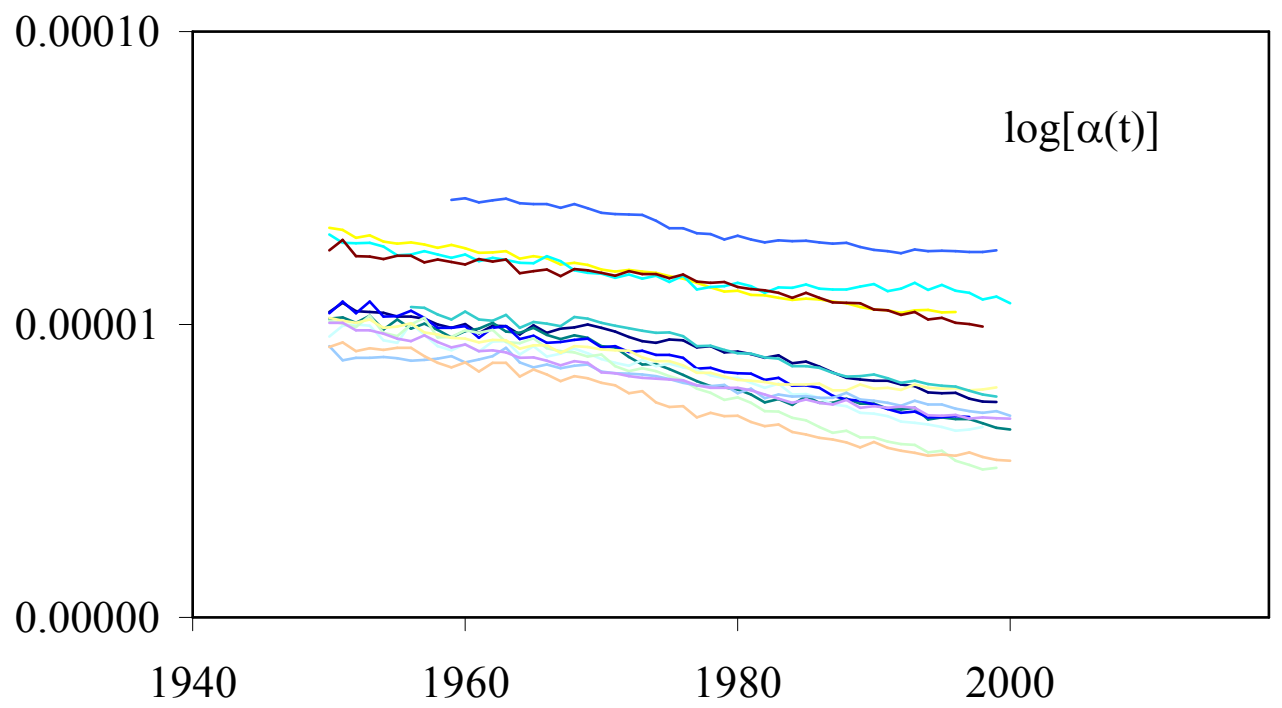

Figure 4b: Estimates of background parameter $\gamma$ in the shifting logistic model (constant $\beta$ ) for 14 countries, females

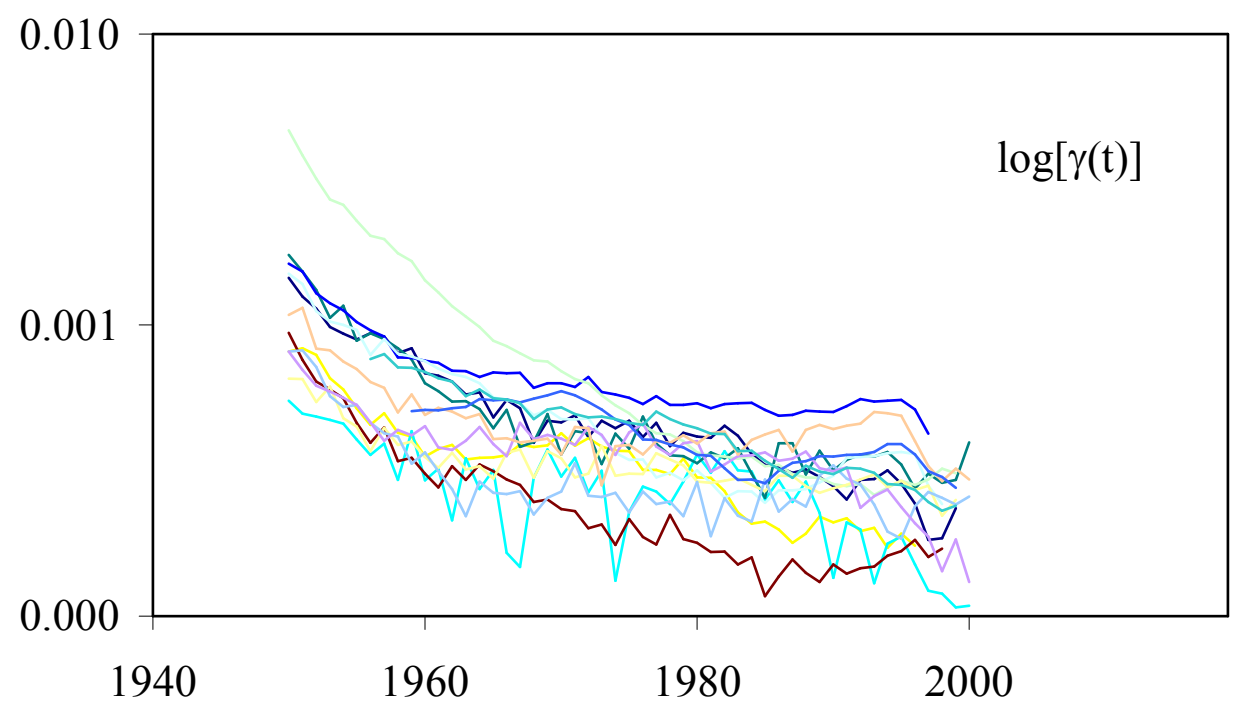


Figure 5: Comparison of alternative projections of death rates in 2000 (1975 base year), Swedish females

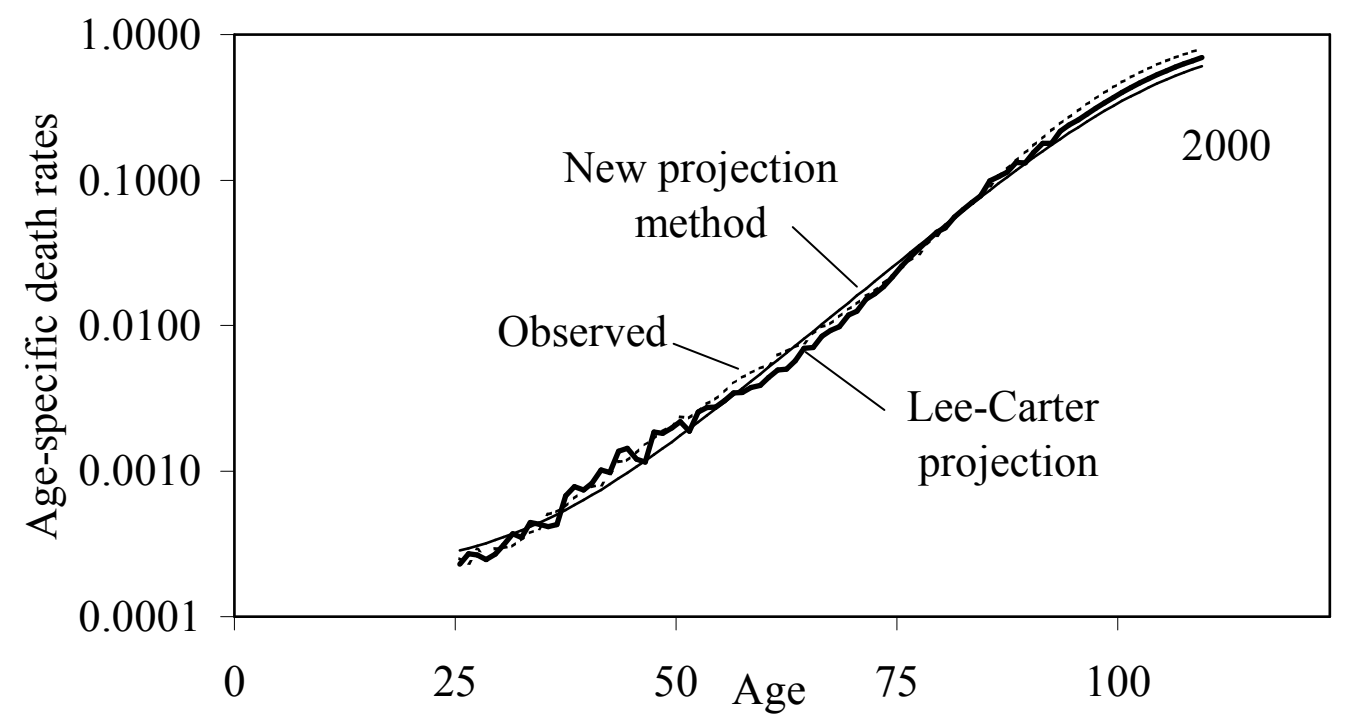

Figure 6: Comparison of alternative projections of death rates to 2100 , Swedish females

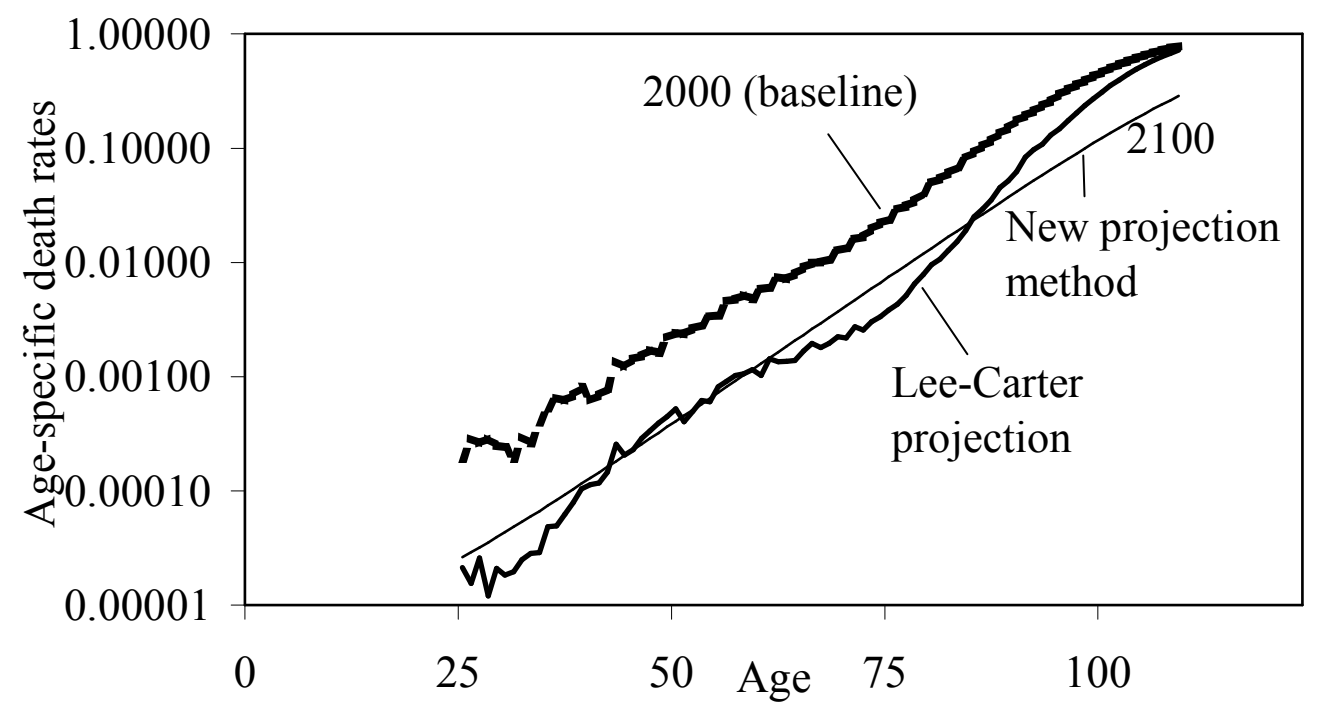




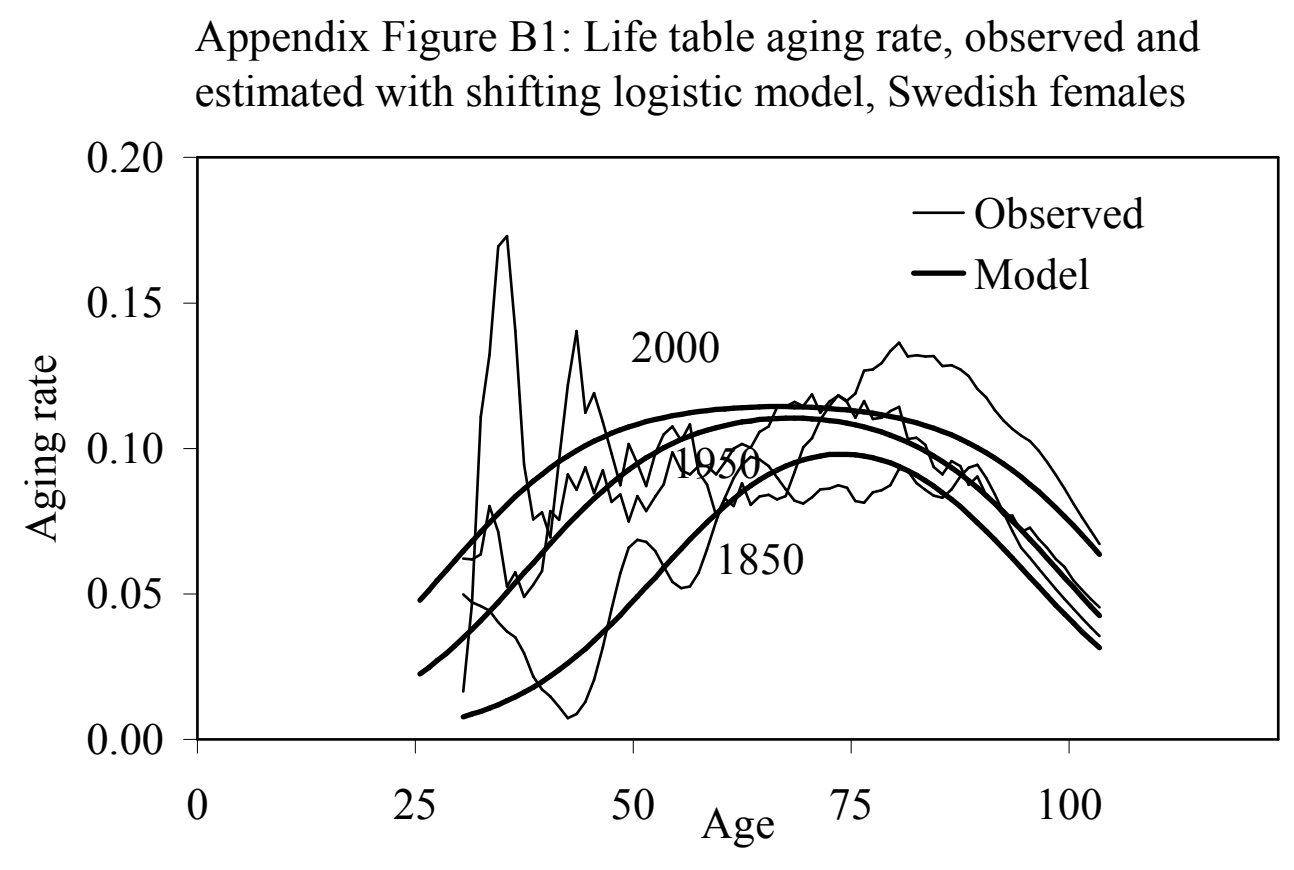

Appendix Figure B2: Senescent component of life table aging rate estimated with shifting logistic model, Swedish females

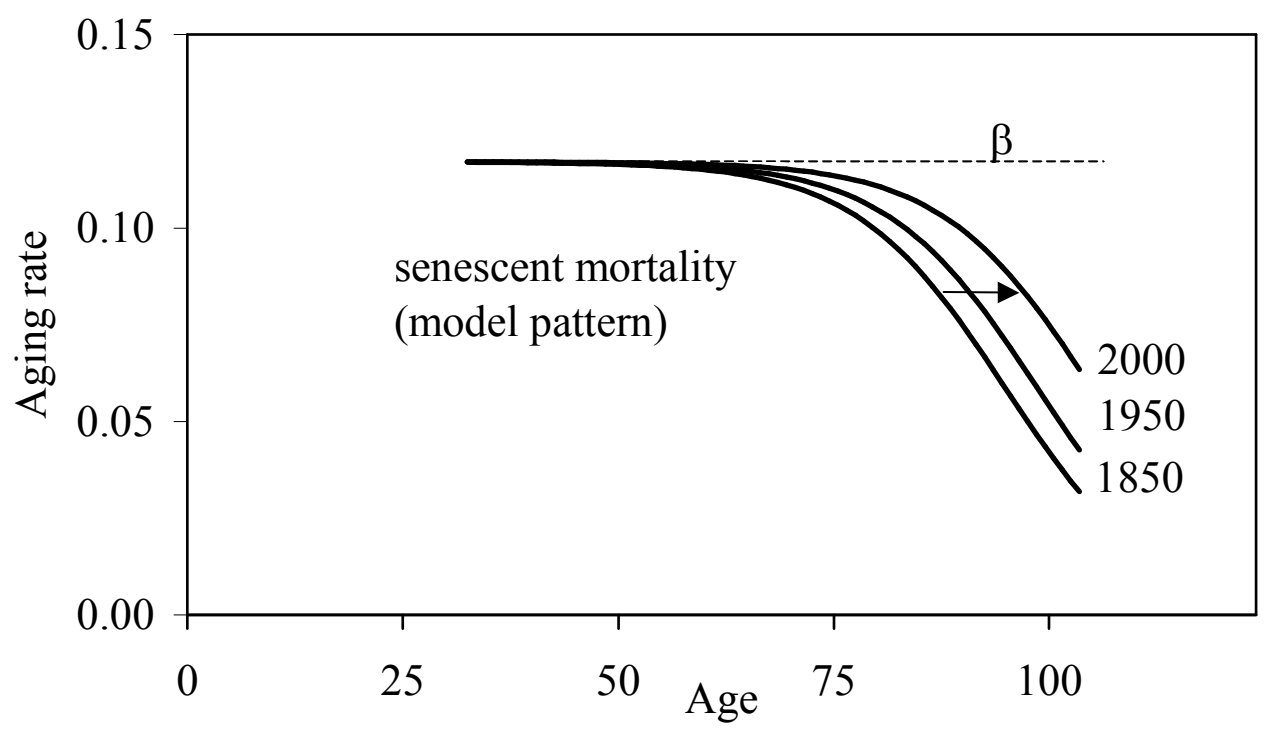


Appendix Figure B3: Background component of life table aging rate estimated with shifting logistic model, Swedish females

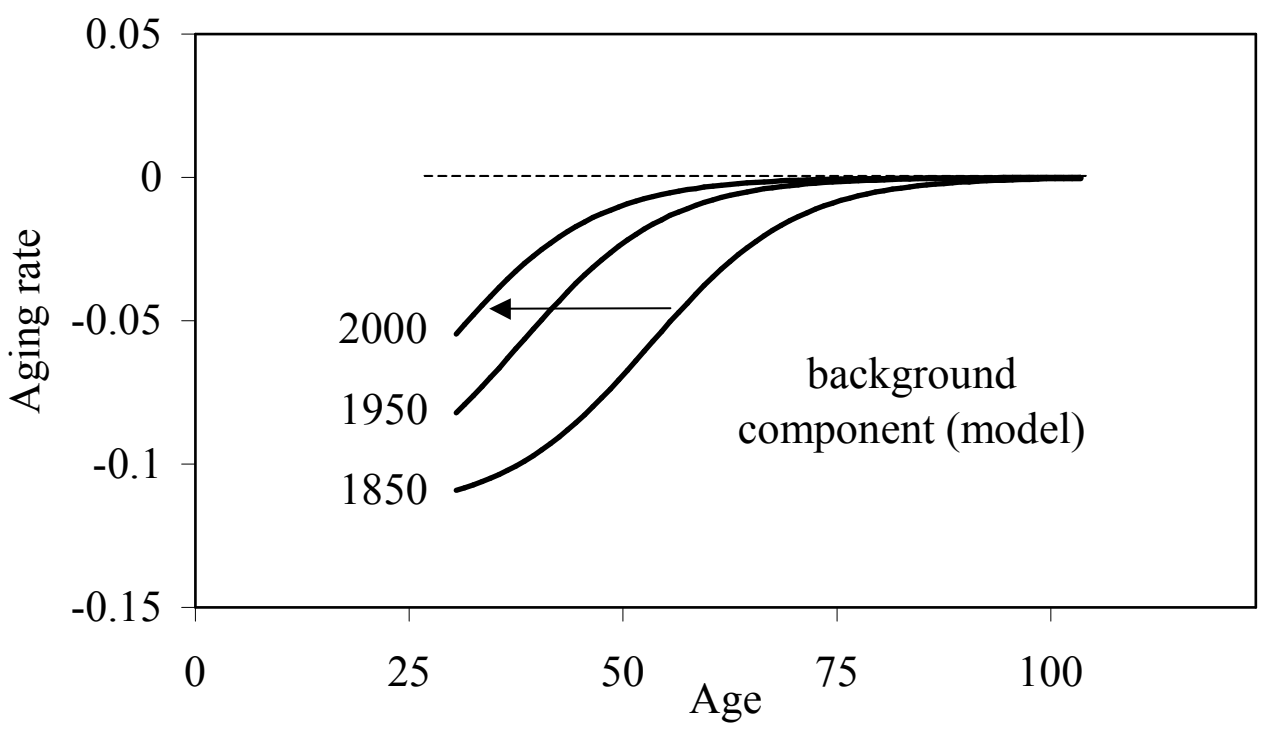

Appendix Figure B4: Senescent and background life table aging rate estimated with shifting logistic model, Swedish females, 1950

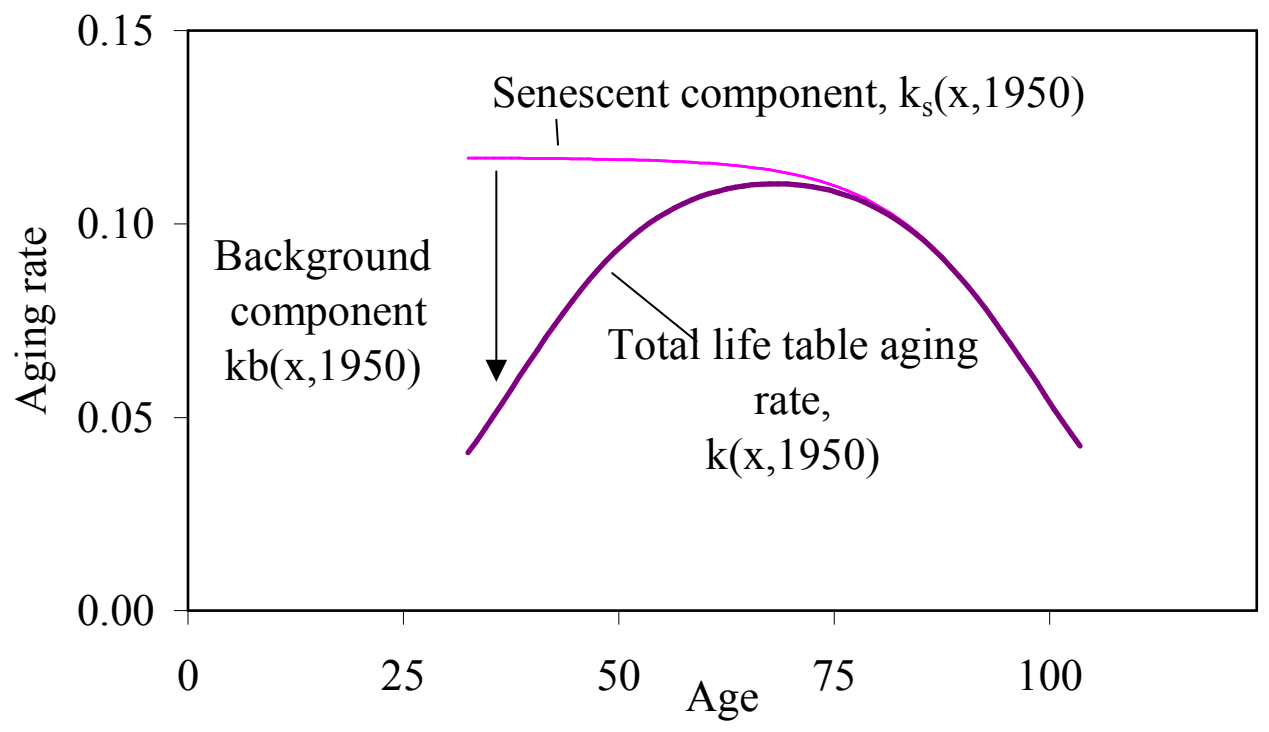


Appendix Figure B5: Rate of mortality improvement, observed and estimated with shifting logistic model, Swedish females

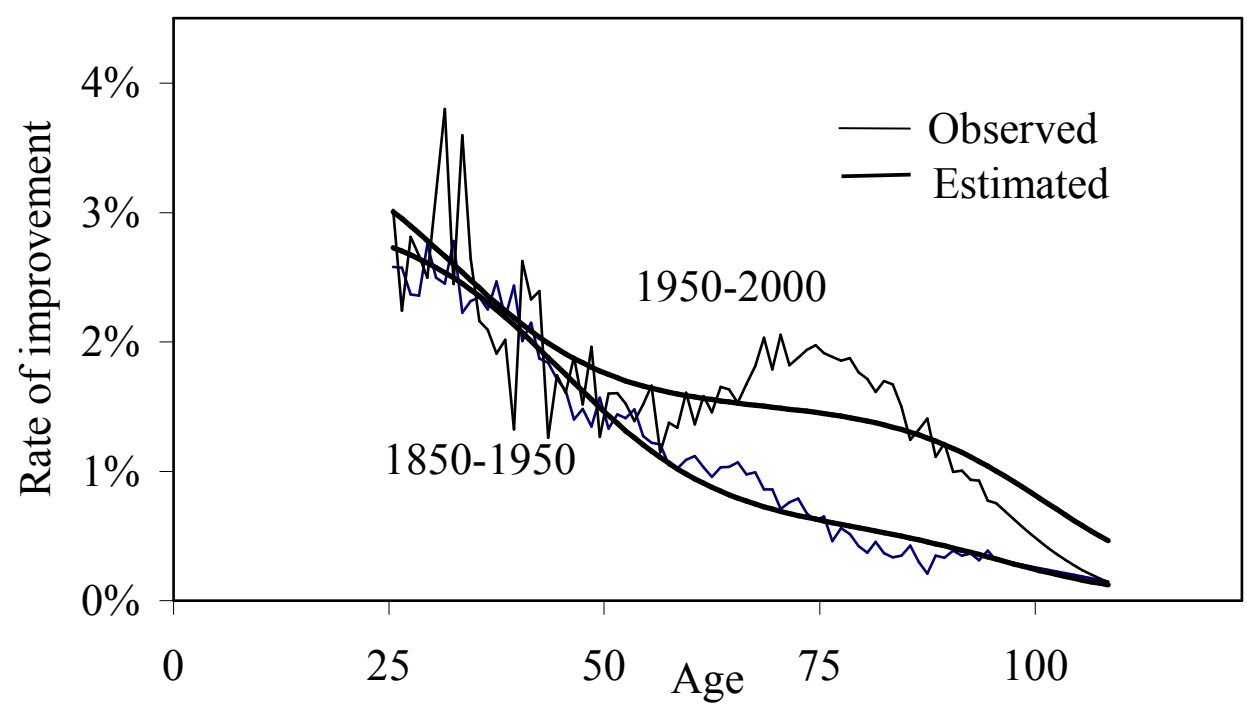

Appendix Figure B6: Senescent component of rate of mortality improvement estimated with shifting logistic model, Swedish females

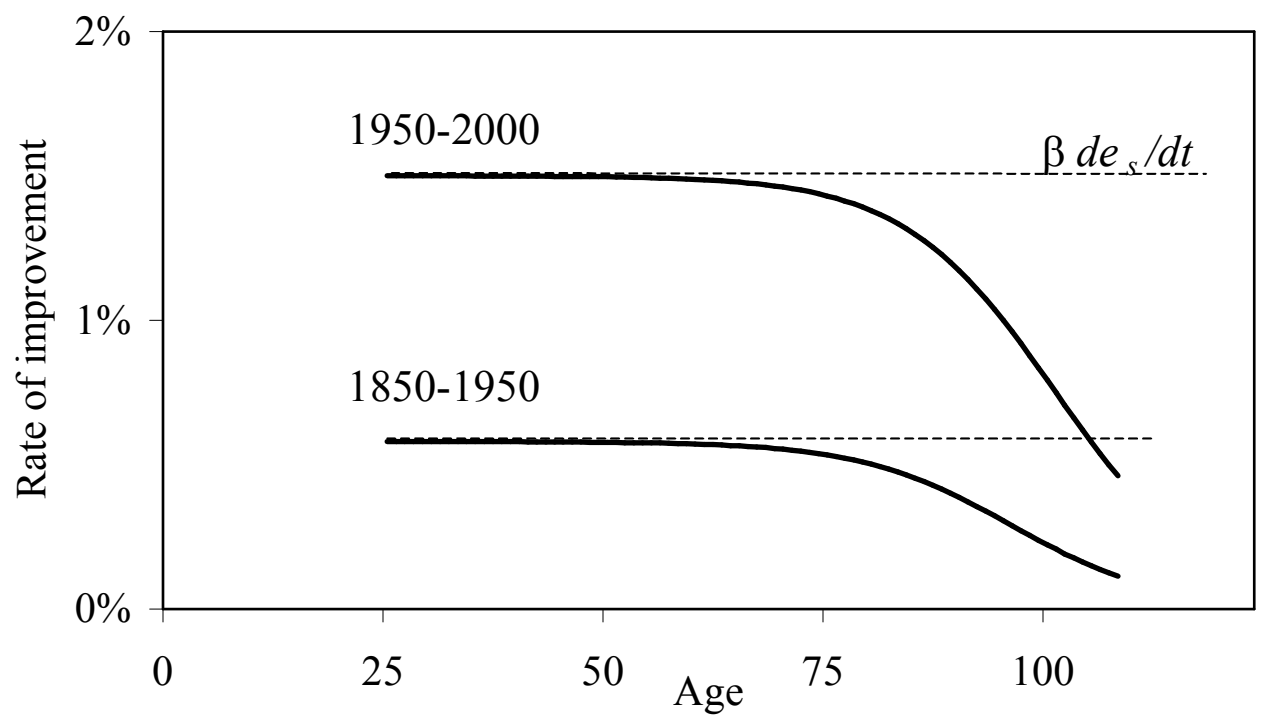


Appendix Figure B7: Background component of rate of mortality improvement estimated with shifting logistic model, Swedish females

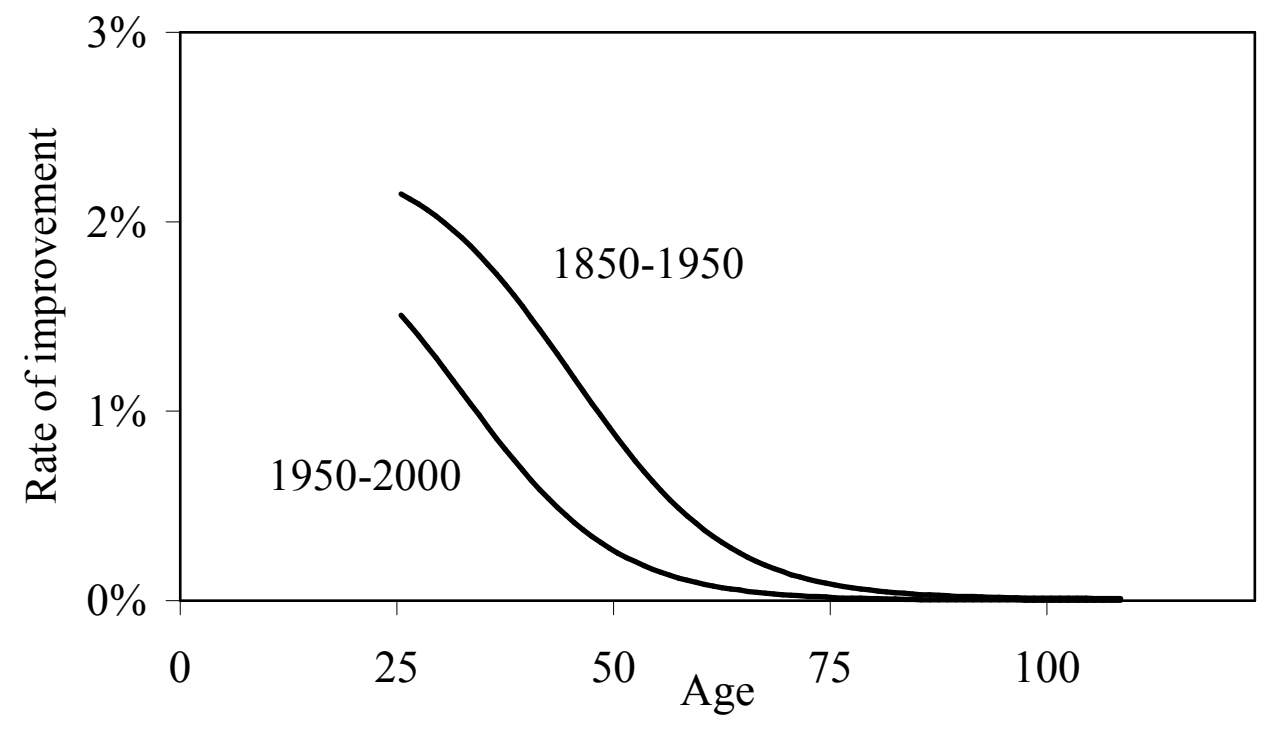

Appendix Figure B8: Decomposition of model estimated rate of mortality improvement, Swedish females

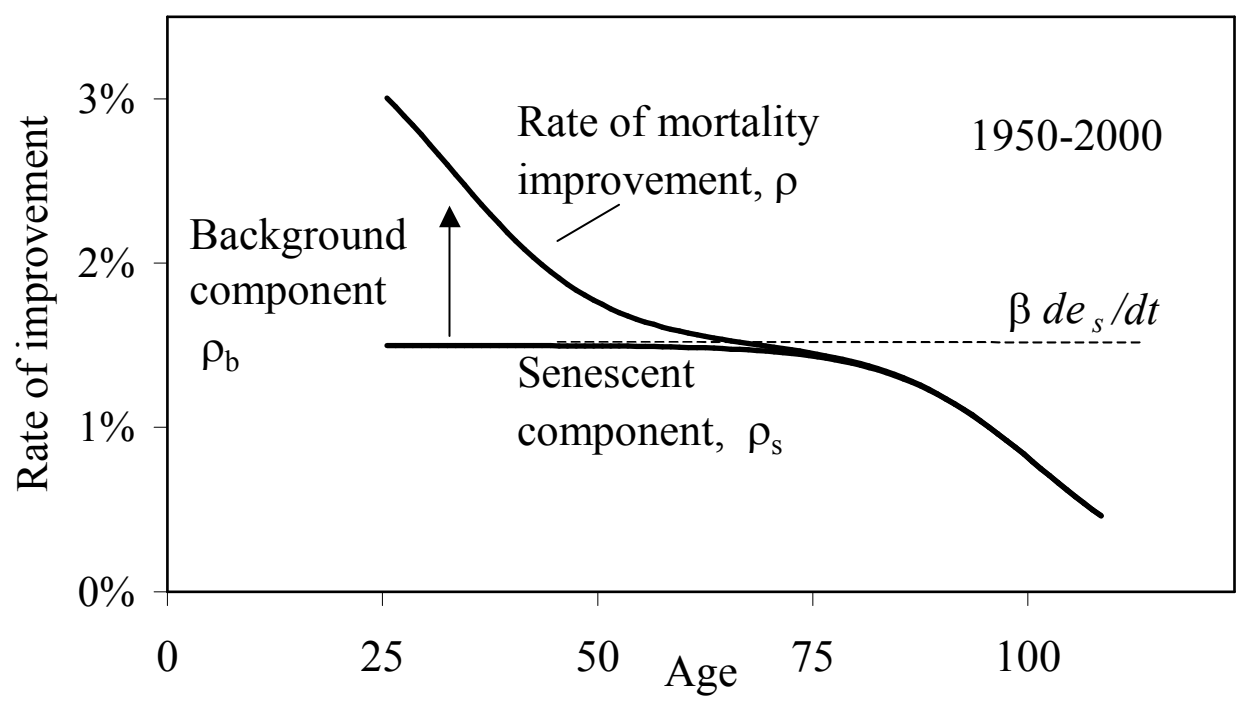


Appendix Figure B9: Rate of mortality improvement estimated with shifting logistic model, females

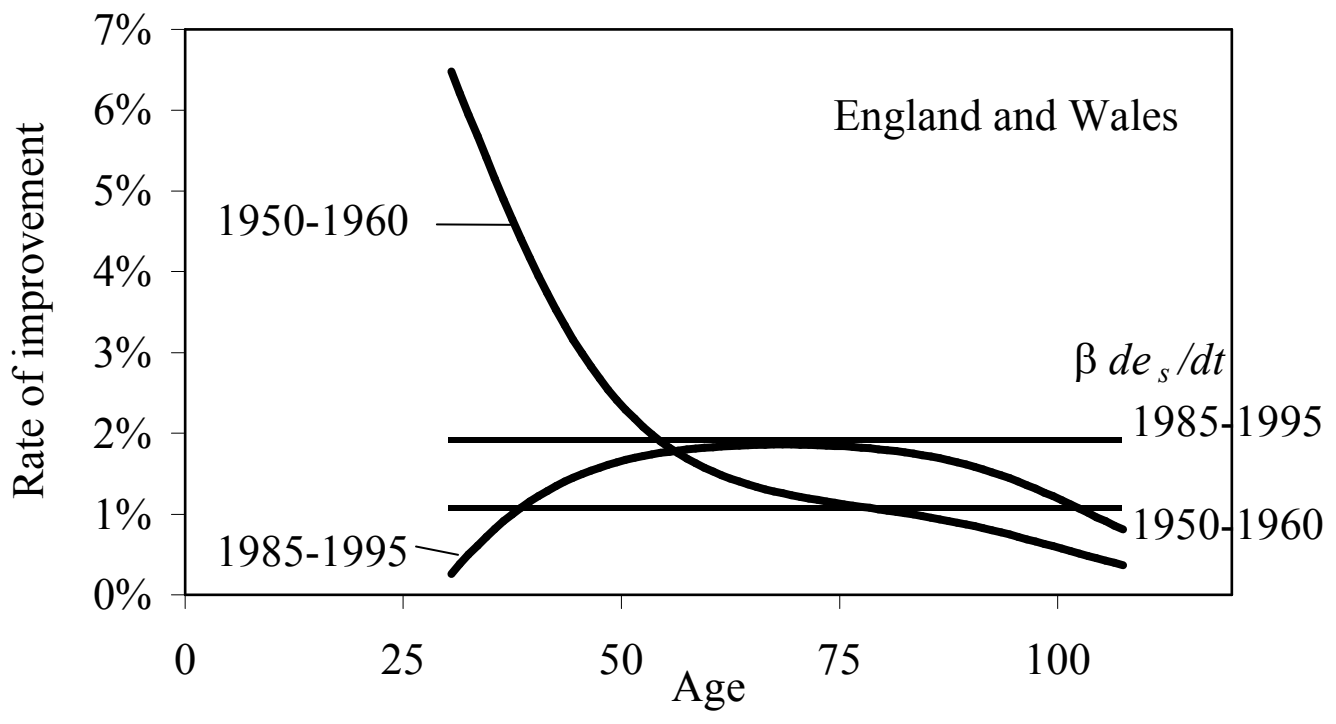

Appendix Figure B10: Rate of mortality improvement estimated with shifting logistic model, females

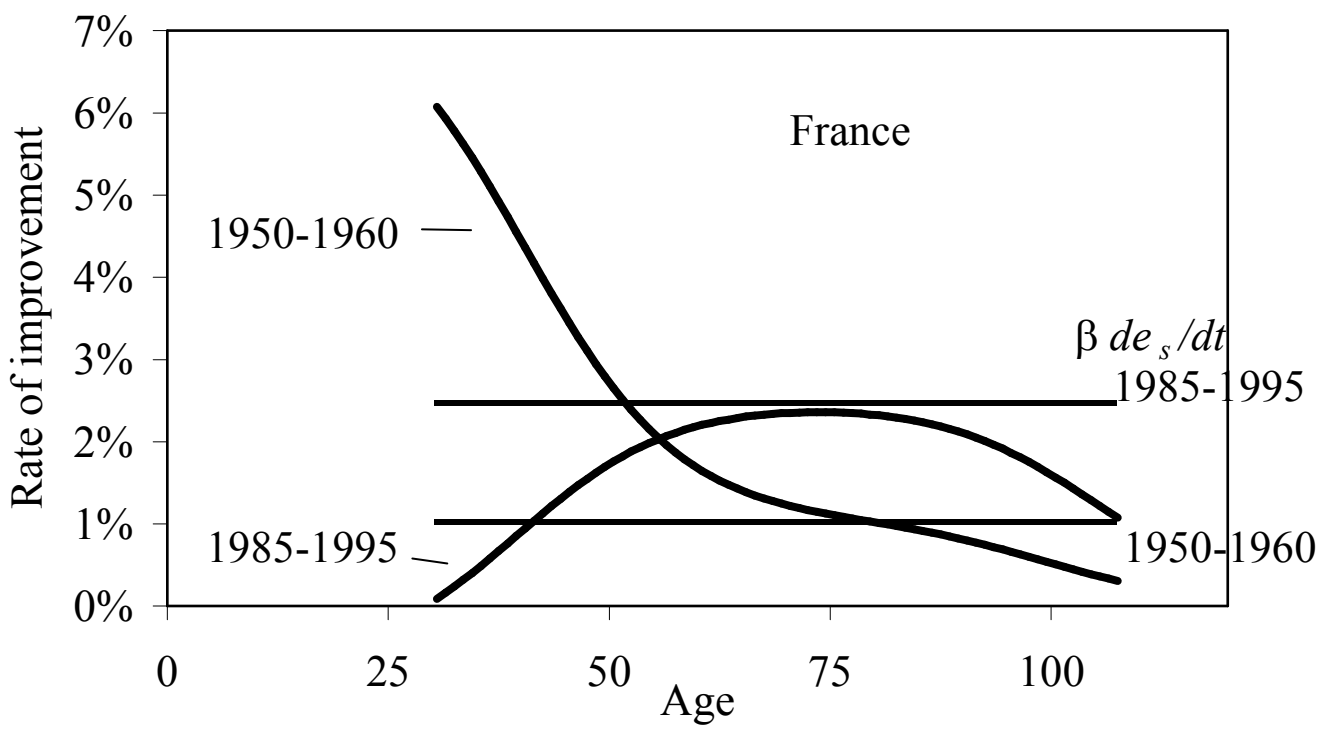


Appendix Figure B11: Rate of mortality improvement estimated with shifting logistic model, females

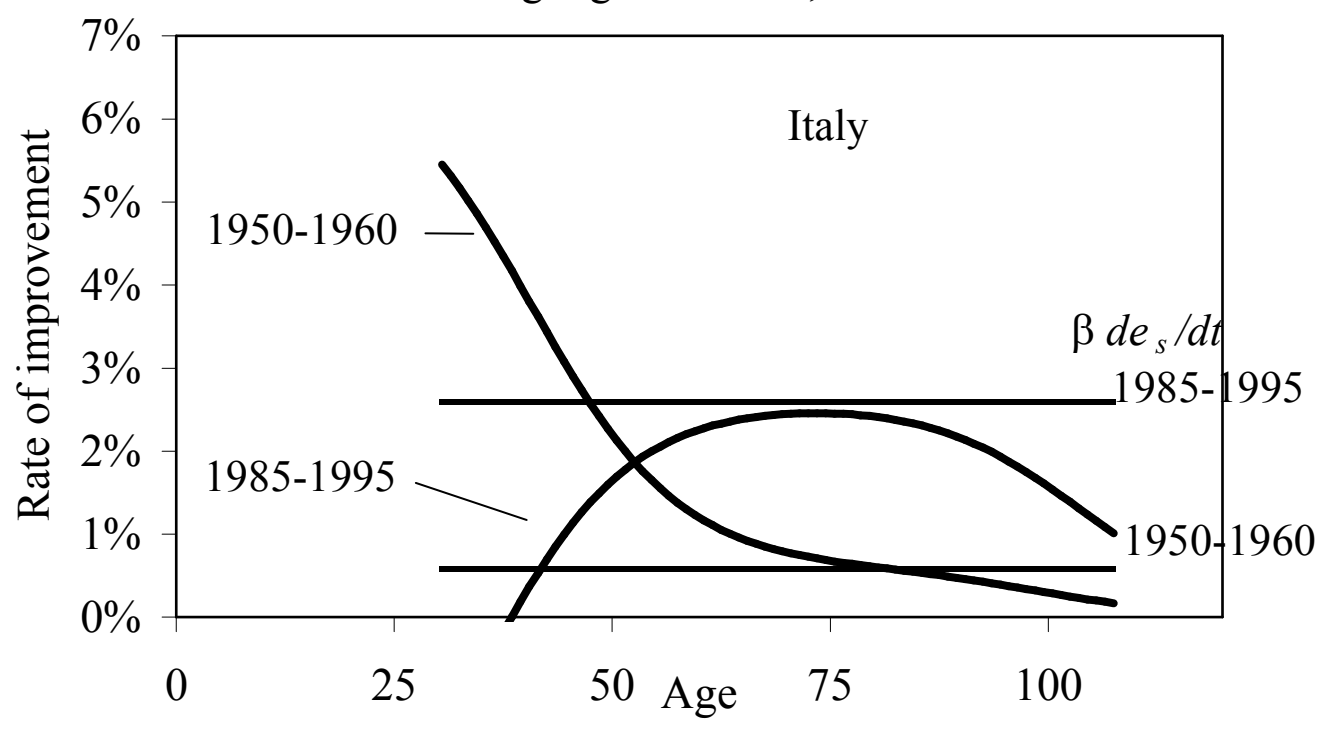

Appendix Figure B12: Rate of mortality improvement estimated with shifting logistic model, females

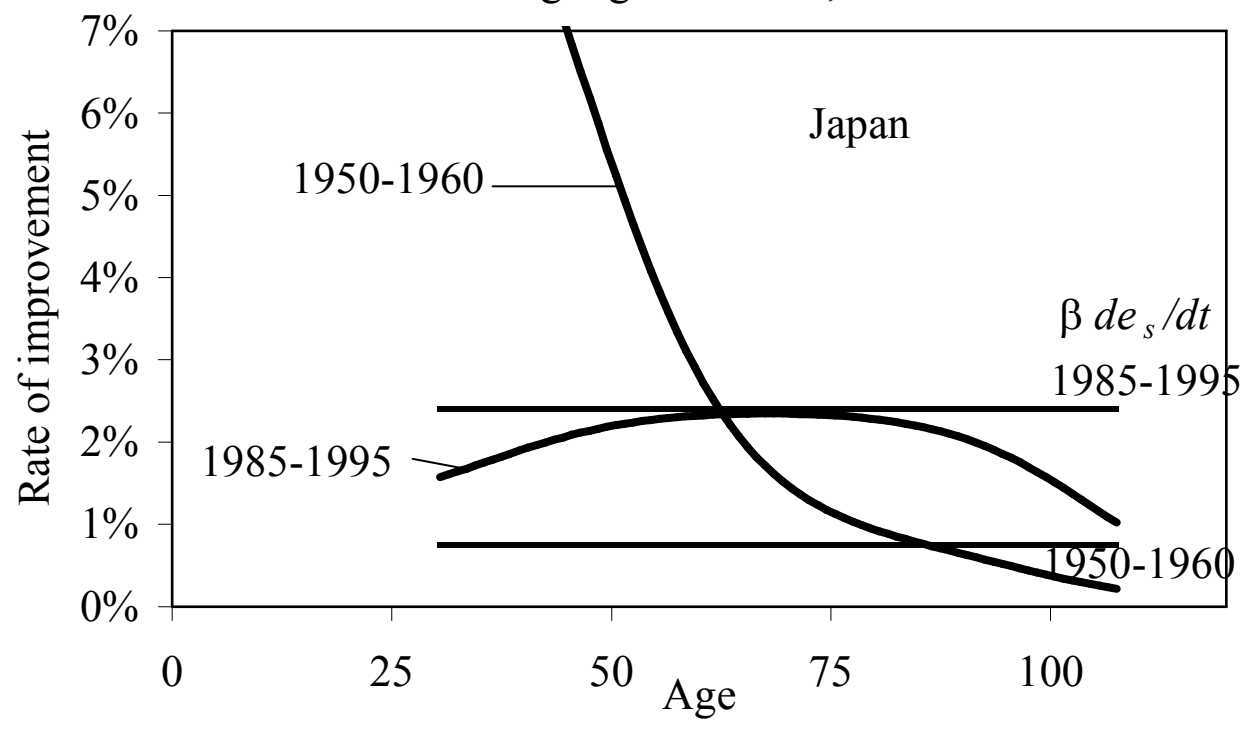




\section{POLICY DIVISION WORKING PAPERS}

If still in print, single copies of up to three working papers from 1989 through 2003 are available free of charge.

Beginning with the 2004 issues, the working papers will no longer be available in print format. Instead they will be distributed electronically. As each new paper is completed subscribers will be notified by e-mail and a link to the paper will be provided.

To subscribe to the Policy Research Division working paper e-mail notification list, or to obtain back issues from 1989 to 2003, please send your request to prdwp@ popcouncil.org.

PDFs of recent issues are available at www.popcouncil.org/publications/wp/prd/rdwplist.html

2004

192 John Bongaarts. "Long-range trends in adult mortality: Models and projection methods."

191 John Koku Awoonor-Williams, Ellie S. Feinglass, Rachel Tobey, Maya N. Vaughan-Smith, Frank K. Nyonator, Tanya C. Jones, and James F. Phillips, "Bridging the gap between evidence-based innovation and national healthsector reform in Ghana."

190 Kelly Hallman, "Socioeconomic disadvantage and unsafe sexual behaviors among young women and men in South Africa."

189 Toshiko Kaneda, Zachary Zimmer, and Zhe Tang, "Differentials in life expectancy and active life expectancy by socioeconomic status among older adults in Beijing."

188 Cynthia B. Lloyd and Monica J. Grant, "Growing up in Pakistan: The separate experiences of males and females."
187 Zachary Zimmer, Xianghua Fang, Toshiko Kaneda, Zhe Tang, and Julia Kwong. "Trends and transitions in children's coresidence with older adults in Beijing municipality."

186 Sajeda Amin and Alaka M. Basu. "Popular perceptions of emerging influences on mortality and longevity in Bangladesh and West Bengal."

185 John Bongaarts. "Population aging and the rising cost of public pensions."

184 Mark R. Montgomery and Paul C. Hewett. "Urban poverty and health in developing countries: Household and neighborhood effects.

\section{3}

183 Agnes R. Quisumbing and Kelly Hallman. "Marriage in transition: Evidence on age, education, and assets from six developing countries." 
182 Paul C. Hewett, Barbara S. Mensch, and Annabel S. Erulkar, "Consistency in the reporting of sexual behavior among adolescent girls in Kenya: A comparison of interviewing methods."

181 Zachary Zimmer, Linda G. Martin, and Hui-Sheng Lin, "Determinants of old-age mortality in Taiwan."

180 Frank K. Nyonator, J. Koku Awoonor-Williams, James F. Phillips, Tanya C. Jones, and Robert A. Miller, "The Ghana Community-based Health Planning and Services Initiative: Fostering evidence-based organizational change and development in a resourceconstrained setting."

179 John Bongaarts and Griffith Feeney, "Estimating mean lifetime."

178 Elizabeth F. Jackson, Patricia Akweongo, Evelyn Sakeah, Abraham Hodgson, Rofina Asuru, and James F. Phillips, "Women's denial of having experienced female genital cutting in northern Ghana: Explanatory factors and consequences for analysis of survey data."

177 John Bongaarts, "Completing the fertility transition in the developing world: The role of educational differences and fertility preferences."

176 Cynthia B. Lloyd and Paul C. Hewett, "Primary schooling in sub-Saharan Africa: Recent trends and current challenges."
175 James F. Phillips, Tanya C. Jones, Frank K. Nyonator, and Shruti Ravikumar, "Evidence-based development of health and family planning programs in Bangladesh and Ghana."

174 Geoffrey McNicoll, "Population and development: An introductory view."

173 Paul Demeny, "Population policy: A concise summary."

172 Zachary Zimmer, Napaporn Chayovan, Hui-Sheng Lin, and Josefina Natividad, "How indicators of socioeconomic status relate to physical functioning of older adults in three Asian societies."

171 Sajeda Amin and Nagah H. AlBassusi, "Wage work and marriage: Perspectives of Egyptian working women."

170 Ravai Marindo, Steve Pearson, and John B. Casterline, "Condom use and abstinence among unmarried young people in Zimbabwe: Which strategy, whose agenda?"

169 Zachary Zimmer and Julia Dayton, "The living arrangements of older adults in sub-Saharan Africa in a time of HIV/AIDS."

168 Paul C. Hewett, Annabel S. Erulkar, and Barbara S. Mensch, "The feasibility of computerassisted survey interviewing in Africa: Experience from two rural districts in Kenya."

* No longer available as a printed publication. Download electronic file from Web site only. 
2002

167* Dominic K. Agyeman and John B. Casterline, "Social organization and reproductive behavior in southern Ghana."

166* Carol E. Kaufman and Stavros E. Stavrou, "'Bus fare, please': The economics of sex and gifts among adolescents in urban South Africa."

165 Kelly Hallman, Agnes R. Quisumbing, Marie Ruel, and Bénédicte de la Brière, "Childcare, mothers' work, and earnings: Findings from the urban slums of Guatemala City."

164 Cynthia B. Lloyd, Cem Mete, and Zeba A. Sathar, "The effect of gender differences in primary school access, type, and quality on the decision to enroll in rural Pakistan."

163 Barbara S. Mensch, Wesley H. Clark, and Dang Nguyen Anh, "Premarital sex in Vietnam: Is the current concern with adolescent reproductive health warranted?"

162 Naomi Rutenberg, Carol E. Kaufman, Kate Macintyre, Lisanne Brown, and Ali Karim, "Pregnant or positive: Adolescent childbearing and HIV risk in South Africa."

161 John Bongaarts, "The end of the fertility transition in the developing world."
160* Julia Dayton and Martha Ainsworth, "The elderly and AIDS: Coping strategies and health consequences in rural Tanzania."

159 Carol E. Kaufman, Shelley Clark, Ntsiki Manzini, and Julian May, "How community structures of time and opportunity shape adolescent sexual behavior in South Africa."

158 Geoffrey McNicoll, "Demographic factors in East Asian regional integration."

157 Zachary Zimmer and Sovan Kiry Kim, "Living arrangements and socio-demographic conditions of older adults in Cambodia."

156 John Bongaarts and Griffith Feeney, "How long do we live?"

155 Zachary Zimmer, Linda G. Martin, and Ming-Cheng Chang, "Changes in functional limitations and survival among the elderly in Taiwan: 1993, 1996, and 1999."

\footnotetext{
* No longer available as a printed publication. Download electronic file from Web site only.
} 